\title{
ARTICLE
}

\section{B cell-intrinsic TBK1 is essential for germinal center formation during infection and vaccination in mice}

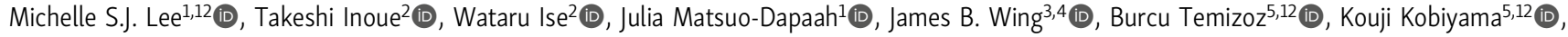 \\ Tomoya Hayashi5,12 (D), Ashwini Patil ${ }^{6}$ (D), Shimon Sakaguchi ${ }^{7}$ (D), A. Katharina Simon ${ }^{8}$ (D), Jelena S. Bezbradica ${ }^{8}$ (D), Satoru Nagatoishi ${ }^{9}$ (D), \\ Kouhei Tsumoto $9,10 \mathbb{D}$, Jun-Ichiro Inoue ${ }^{9}$ D, Shizuo Akira ${ }^{11} \mathbb{D}$, Tomohiro Kurosaki ${ }^{2}$ D, Ken J. Ishii, ${ }^{5,11,12} \mathbb{D}$, and Cevayir Coban ${ }^{1,11,12}$ (D)
}

The germinal center (GC) is a site where somatic hypermutation and clonal selection are coupled for antibody affinity maturation against infections. However, how GCs are formed and regulated is incompletely understood. Here, we identified an unexpected role of Tank-binding kinase-1 (TBK1) as a crucial B cell-intrinsic factor for GC formation. Using immunization and malaria infection models, we show that TBK1-deficient B cells failed to form GC despite normal Th cell differentiation, although some malaria-infected B cell-specific TBK1-deficient mice could survive by GC-independent mechanisms. Mechanistically, TBK1 phosphorylation elevates in B cells during GC differentiation and regulates the balance of IRF4/BCL6 expression by limiting CD40 and BCR activation through noncanonical NF-KB and AKT ${ }^{\mathrm{T} 308}$ signaling. In the absence of TBK1, CD40 and BCR signaling synergistically enhanced IRF4 expression in Pre-GC, leading to BCL6 suppression, and therefore failed to form GCs. As a result, memory B cells generated from TBK1-deficient B cells fail to confer sterile immunity upon reinfection, suggesting that TBK1 determines $B$ cell fate to promote long-lasting humoral immunity.

\section{Introduction}

Germinal centers (GCs) are highly dynamic structures formed in secondary and tertiary lymphoid organs and play a key role in humoral immune responses against pathogens and during vaccination. Induction of GCs allows antigen-activated B cells to be selected for the production of affinity-matured antibodies through the process of somatic hypermutation and clonal selection and then to exit GCs to become antigen-specific longlived plasma cells and memory B cells. The anatomical structure and function of GCs have been studied for a long time (Victora and Nussenzweig, 2012), but only recently has information been gathered about how $\mathrm{B}$ cells are guided through the development of GCs. Upon antigen encounter, B cells rapidly proliferate and differentiate into multipotent precursor cells that have the potential to diverge into two distinct fates: either GC or extrafollicular (EF) responses (Taylor et al., 2012). Collective studies suggested that the combination of multiple factors, including $\mathrm{BCR}$, costimulatory receptors, and cytokines, leads to differential transcriptional regulation that determines the fate of antigenactivated B cells to commit into GCs (Cyster and Allen, 2019; Song and Matthias, 2018). Induction of the GC reaction is often the desirable outcome of an infection or vaccine to provide antigen-specific long-lasting humoral immunity. Conversely, the induction of GC-independent EF responses in several disease models and vaccinations results in early acute production of short-lived plasmablasts (Elsner and Shlomchik, 2020). The intrinsic and extrinsic factors that determine the fate of antigenactivated B cells, whether to enter GC reactions or to commit to EF responses, are not yet well defined.

$B$ cells recognize antigens through the $B C R$ and migrate to the $\mathrm{B}-\mathrm{T}$ cell border to present the antigen to cognate $\mathrm{CD} 4^{+} \mathrm{T}$ cells with the engagement of costimulatory molecules, such as CD40L, CD80, CD86, and inducible T cell costimulator (ICOS) ligand (ICOSL), to drive the differentiation of $\mathrm{T}$ follicular helper (Tfh) cells. The interaction between antigen-activated B cells

${ }^{1}$ Division of Malaria Immunology, Department of Microbiology and Immunology, The Institute of Medical Science, The University of Tokyo, Tokyo, Japan; ${ }^{2}$ Laboratory of Lymphocyte Differentiation, Immunology Frontier Research Center, Osaka University, Osaka, Japan; ${ }^{3}$ Laboratory of Human Immunology (Single Cell Immunology), Immunology Frontier Research Center, Osaka University, Osaka, Japan; ${ }^{4 H}$ uman Single Cell Immunology Team, Center for Infectious Disease Education and Research, Osaka University, Osaka, Japan; ${ }^{5}$ Division of Vaccine Science, Department of Microbiology and Immunology, The Institute of Medical Science, The University of Tokyo, Tokyo, Japan; ${ }^{6}$ Combinatics Inc., Tokyo, Japan; ${ }^{7}$ Laboratory of Experimental Immunology, Immunology Frontier Research Center, Osaka University, Osaka, Japan; ${ }^{8}$ The Kennedy Institute of Rheumatology, Nuffield Department of Orthopaedics, Rheumatology and Musculoskeletal Sciences, University of Oxford, Oxford, UK; ${ }^{9}$ Research Platform Office, The Institute of Medical Science, The University of Tokyo, Tokyo, Japan; ${ }^{10}$ Department of Bioengineering, Graduate School of Engineering, The University of Tokyo, Tokyo, Japan; ${ }^{11}$ Immunology Frontier Research Center, Osaka University, Osaka, Japan; ${ }^{12}$ International Vaccine Design Center, The Institute of Medical Science, The University of Tokyo, Tokyo, Japan.

Correspondence to Cevayir Coban: ccoban@ims.u-tokyo.ac.jp; Ken J. Ishii: kenishii@ims.u-tokyo.ac.jp.

(C) 2021 Lee et al. This article is distributed under the terms of an Attribution-Noncommercial-Share Alike-No Mirror Sites license for the first six months after the publication date (see http://www.rupress.org/terms/). After six months it is available under a Creative Commons License (Attribution-Noncommercial-Share Alike 4.0 International license, as described at https://creativecommons.org/licenses/by-nc-sa/4.0/). 
and cognate Tfh cells, through physical interaction and cytokines, leads to maturation of Tfh cells and GC formation. The strength of BCR affinity and T cell help through CD40 signaling has been demonstrated to regulate GC initiation and determine the fate of GC B cells (Shinnakasu and Kurosaki, 2017; Laidlaw and Cyster, 2021). GC B cells, with intermediate BCR affinity and CD40 help, tend to differentiate into memory $B$ cells, while high $B C R$ affinity with strong CD40 signaling drives B cells to differentiate into plasma cells fate. Recent studies also showed that $\mathrm{CD} 40$ and BCR signaling is altered as naive B cells differentiate into GC B cells to regulate clonal selection in the light zone (Luo et al., 2019, 2018). However, the B cell-intrinsic factors and molecular mechanisms that regulate the dynamics of CD40 and BCR signaling to initiate GC differentiation are not fully understood.

TANK-binding kinase-1 (TBK1) is a serine/threonine kinase that is known for its role in innate immunity, especially for type I IFN (IFN-I) production upon nucleic acid recognition (Hemmi et al., 2004; Ishii et al., 2008). Apart from its role in IFN-I production via phosphorylation of IFN regulatory factor $3 / 7$ (IRF3/7), TBK1 is also involved in various signaling pathways in a cell type-specific manner (Xiao et al., 2017; Jin et al., 2012; Zhao et al., 2018) and in adaptive immunity (Jin et al., 2012; Yu et al., 2015; Pedros et al., 2016; Marichal et al., 2011). Importantly, silencing Tbk1 expression in CD4 T cells using shRNA suggested the role of TBK1 in Tfh cell maturation through ICOS signaling (Pedros et al., 2016), while TBK1 signaling in B cells was shown to negatively regulate IgA antibody class switching (Jin et al., 2012). Moreover, Tbkl is one of the genes up-regulated in GC B cells upon 4-hydroxy-3-nitrophenylacetyl (NP)-CGG immunization (Kaji et al., 2012), suggesting that TBK1 may have a role in GC formation. However, whether TBK1 plays a critical role in $\mathrm{Tfh}-\mathrm{B}$ cell communications remains unclear.

Unlike most infectious diseases against which long-lasting protection is conferred through induction of immune memory after recovery from primary infection, malaria is exceptional. Human malaria infection only induces partial immunity after subsequent repeated infections (Portugal et al., 2013). An individual remains susceptible to repeated malaria infection despite gaining partial immunity that protects from severe complications (Coban et al., 2018). How the GC is regulated during malaria infection and impairs immune memory that confers sterile protection is not fully understood (Akkaya et al., 2020b). Both host and parasite factors are thought to contribute to the development or suppression of protective humoral immunity (Saito et al., 2017; Akkaya et al., 2020a).

Here, using both malaria infection and immunization models, we identified B cell-intrinsic TBK1 as an important molecule involved in regulating GC differentiation. We found that phosphorylation of TBK1 increased in B cells during GC differentiation. Notably, Tbk1 deletion in B cells led to impaired GC formation and therefore increased susceptibility to a nonlethal malaria infection. Memory B cells generated in the absence of TBK1-dependent GC failed to confer sterile immunity upon reinfection challenge. Although TBK1-deficient B cells could be activated to differentiate into GC precursor cells (Pre-GC), the fate of these cells was distinct from that of TBK1-sufficient
B cells. We found that TBK1 negatively regulates both CD40 and BCR signaling in Pre-GC. Mechanistically, increased CD40induced RelB expression in TBK1-deficient Pre-GC enhanced IRF4 expression that subsequently suppressed B-cell lymphoma 6 (Bcl6) expression, the master regulator of GC formation. Unlike naive $B$ cells, BCR activation further enhanced CD40-induced IRF4 expression in Pre-GC in a TBK1-dependent manner. This study revealed a crucial role of B cell-intrinsic TBK1 as a determinant of GC commitment through the fine tuning of CD40 and BCR signaling.

\section{Results}

\section{TBK1 in B cells is indispensable for GC formation}

Murine malaria infection with Plasmodium yoelii nonlethal $(\mathrm{P} y \mathrm{NL})$ has been shown to induce robust Tfh cell-dependent GC formation (Arroyo and Pepper, 2020; Pérez-Mazliah et al., 2015; Fig. S1, A and B). In fact, Tfh cell-deficient mice ( $\left.C d 4^{\text {cre } B c l 6} 6^{\mathrm{f} / \mathrm{f}}\right)$ infected with PyNL could not generate Tfh cells and form GCs and thus could not recover from the infection, suggesting GC-dependent humoral immunity is responsible for the selfrecovery from $\mathrm{P} y \mathrm{NL}$ infection (Fig. S1, C-E). To investigate how TBK1 plays a critical role in Tfh-B cell communications, we first investigated the role of TBK1 at distinct stages of GC dif-

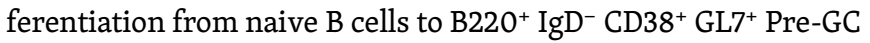
and $\mathrm{B}_{220^{+}} \mathrm{IgD}^{-} \mathrm{CD} 38^{-} \mathrm{GL}^{+}$mature GC B cells. To examine the phosphorylation activity of TBK1 at different stages of GC differentiation, we purified splenic naive B cells, Pre-GC, and mature GC B cells on day 0, day 9, and day 30 after PyNL infection, respectively, and performed Western blot analysis. We found that TBK1 was constitutively phosphorylated in naive B cells from mouse (Fig. $1 \mathrm{~A}$ ) and human peripheral blood mononuclear cells (PBMCs; Fig. S2 A). Interestingly, both TBK1 protein expression and TBK1 phosphorylation increased in Pre-GC and GC B cells compared with naive B cells (Fig. 1 A).

Next, to investigate the role of TBK1 in GC formation, B cell-intrinsic TBK1-deficient mice $\left(\mathrm{Mbl}^{\text {cre }} \mathrm{Tbkl}^{\mathrm{f} / \mathrm{f}}\right.$ mice $[\mathrm{B}$ $\mathrm{Tbk1}^{\left.{ }^{-I}\right]}$ ) were generated (Fig. S2 B). The deletion of Tbk1 in B cells did not impair normal B cell development in the spleen, peritoneum, and bone marrow (Fig. S2, C and D). However, TBK1 deficiency in B cells led to impaired GC formation (Fig. 1, B-D) and significantly poor recovery from PyNL infection; eventually, $60 \%$ of the mice succumbed to death (Fig. 1, E and F). To address whether the involvement of TBK1 in GC formation is limited to malaria infection, we immunized mice with 4hydroxy-5-iodo-3-nitrophenyl (NIP)-OVA with alum. After immunization, TBK1-deficient B cells, similarly to infection, were found to have severely impaired GC formation in the draining LNs and spleens (Fig. 1, G and $\mathrm{H}$ ).

However, despite the lack of GC formation in $\mathrm{B} \mathrm{Tbk1}^{1-}$ mice, robust class-switched antibody responses were still detected in the serum upon either malaria infection or immunization, albeit significantly less and with lower IgG1 antibody avidity (Fig. S3, A-C). In addition, the absence of $\mathrm{GC}$ in those $\mathrm{B} \mathrm{Tbk1^{-1- }}$ mice did not affect IgG class switching, which is in line with the fact that class-switch recombination happens before B cells enter GC reactions (Roco et al., 2019). 

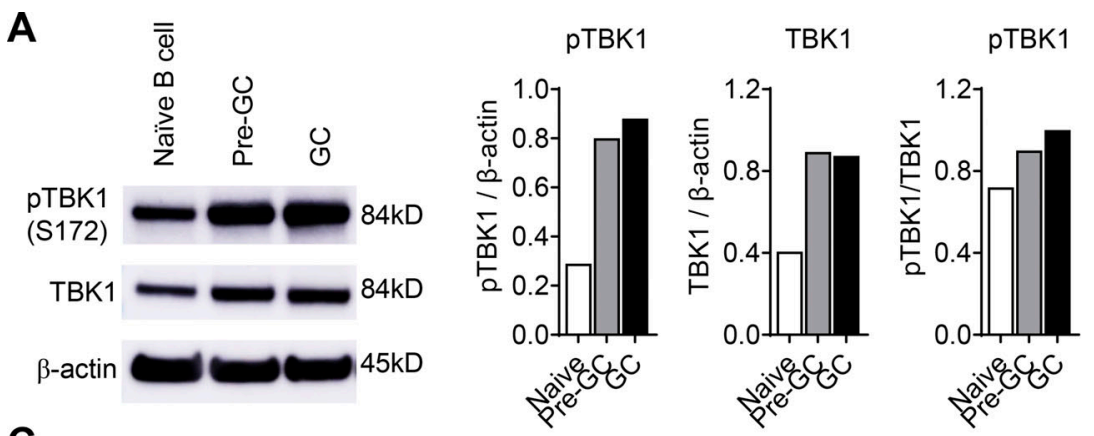

B

C
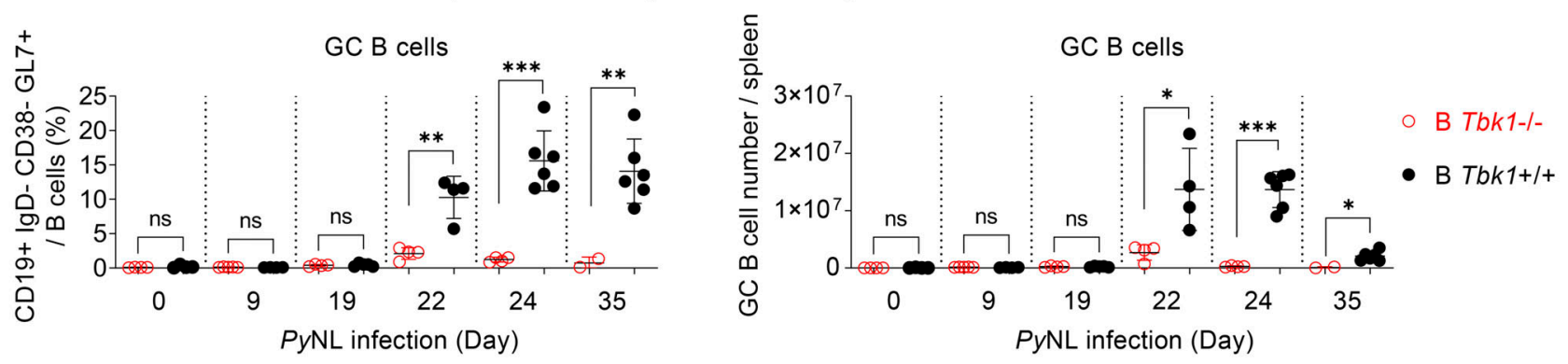

D

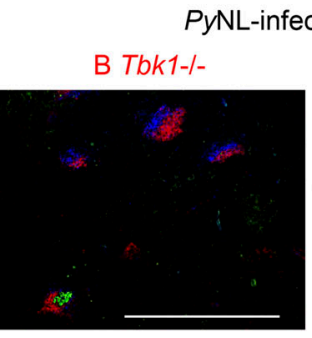

CD4 IgD GL7
$E$

B Tbk1+1+

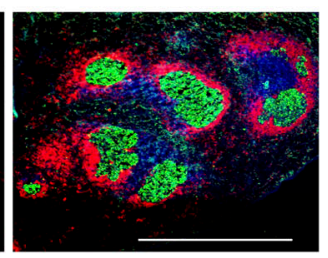

G

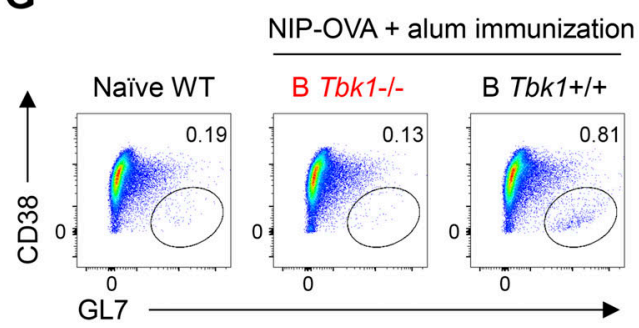

B Tbk1+1+ $\theta$ B Tbk1-I-

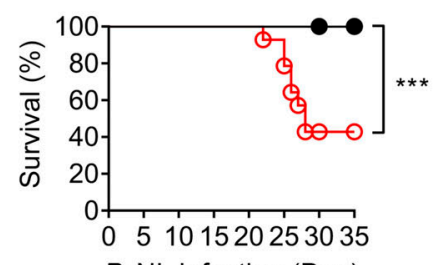

PyNL infection (Day)
F - B Tbk1+1+

$-\odot$ B Tbk1-/- Survived

+ B Tbk1-l-Died †

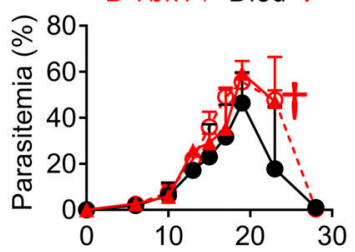

PyNL infection (Day)

Figure 1. TBK1 is involved in GC B cell differentiation. (A) Protein expression and phosphorylation of TBK1 in purified naive B cells from naive mice, Pre-GC B cells from day 9 PyNL-infected mice, and GC B cells from day 30 PyNL-infected mice, pooled from two mice per group. Graph shows the quantitative band intensity normalized to actin control or total TBK1 protein. (B) Representative FACS analysis of GC B cell population in the spleen on day 24 after PyNL infection. Plots are gated on $\mathrm{CD}_{19}{ }^{+} \mathrm{IgD} \mathrm{D}^{-}$cells. (C) Proportions and cell numbers of the GC B cell population in the spleen of PyNL-infected mice over time. $n=$ 4-6 mice/group at each time point from day 0 to day $24 ; n=2-6$ mice/group at day 35. (D) Immunohistochemical analysis of spleens from B Tbk1 ${ }^{-1-}$ and B $\mathrm{Tbk1}^{+/+}$mice that recovered from PyNL infection on day 35 after infection. Staining of CD4 (blue), expressed in CD4 T cells; lgD (red), expressed in mature

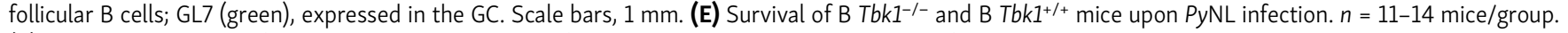

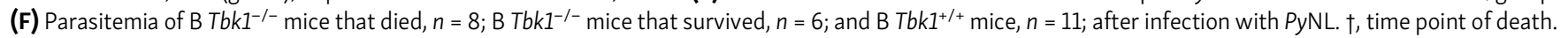
(G) Representative FACS plots and percentages of splenic GC B cell population among total B cells $14 \mathrm{~d}$ and $21 \mathrm{~d}$ after immunization with NIP-OVA with alum

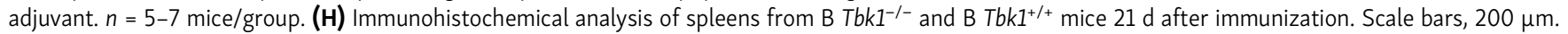
Each dot represents an individual mouse. Data are representative of two (A) or three (G) independent experiments and pooled from five (C) or three (E and F) independent experiments, representative of at least two $(\mathrm{D})$ or three $(\mathrm{H})$ biological replicates. Data are shown as mean $\pm \mathrm{SD} .{ }^{*}, \mathrm{P}<0.05 ;{ }^{* *}, \mathrm{P}<0.01$; ${ }^{* * *}, \mathrm{P}<$ 0.001; unpaired Student's $t$ test (C), Mann-Whitney $t$ test (G), or log-rank (Mantel-Cox) test (E). Source data are available for this figure: SourceData F1.

Although B cell-intrinsic TBK1 was not required for antibodysecreting cell (ASC) formation (Fig. S3 D), the lack of GC in $\mathrm{B} \mathrm{Tbk1}^{-1-}$ mice suggests that those ASCs in B Tbk1 ${ }^{-1-}$ mice were of GC-independent origin and therefore had a lower capacity of antibody production. Collectively, these data suggested that B cell-intrinsic TBK1 is absolutely required for GC formation but is dispensable for ASC differentiation. 


\section{Th cell formation is independent of B cell-intrinsic TBK1}

GC formation relies on cytokines and costimulatory signals from cognate Tfh cells (Nutt and Tarlinton, 2011). Interaction between antigen-activated $\mathrm{B}$ cells and cognate $\mathrm{CD} 4^{+} \mathrm{T}$ cells at the border of the B cell follicle drives Tfh cell differentiation. Tfh cells then signal cognate activated B cells to further differentiate into GC $B$ cells, while signals from GC B cells are important to sustain Tfh cell maintenance. We therefore sought to determine whether the defect in GC formation in the absence of TBK1 in B cells was due to impaired B cell signals to drive Tfh cell formation. Surpris-

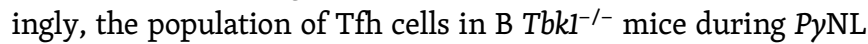
infection was comparable to the WT counterparts in a timecourse analysis up to day 22 , despite the lack of GC in B $\mathrm{Tbk1}^{-/-}$at this time point (Fig. $2 \mathrm{~A}$ ). However, the Tfh cell population was unsustainable at a later time point on day 24 in B $\mathrm{Tbk1}^{-1-}$ mice (Fig. $2 \mathrm{~A}$ ). To address the functionality of these $\mathrm{Tfh}$ cells, we further examined the expression of BCL6, the master regulator of Tfh cells, IL-21, and ICOS, which determine the differentiation and functionality of $\mathrm{Tfh}$ cells (Nurieva et al., 2009; Vogelzang et al., 2008), on day 24 after infection. While the expression of BCL6 and IL-21 increased as T cells differentiated and matured into a Tfh cell population (Fig. 2 B), Tfh cells induced by Tbk1-deficient B cells expressed BCL6 and IL-21 (Fig. 2 C) comparable to that in WT B cells, suggesting Tbkl deficiency in B cells did not impair cognate $\mathrm{T}$ cell priming for $\mathrm{Tfh}$ cell differentiation. Furthermore, ICOS expression on activated $\mathrm{CD}^{+} \mathrm{T}$ cells $\left(\mathrm{CXCR5}{ }^{-} \mathrm{PD}^{+}\right)$, pre-Tfh cells $\left(\mathrm{CXCR} 5^{\text {lo }} \mathrm{PDI}^{+}\right)$, and mature Tfh cells (CXCR5 ${ }^{\text {hi }} \mathrm{PDI}^{+}$) was not suppressed in $\mathrm{B} \mathrm{Tbk1^{-/- }}$ mice (Fig. $2 \mathrm{C}$ ), suggesting that Tbk1-deficient $B$ cells were able to interact with and activate $\mathrm{CD} 4^{+} \mathrm{T}$ cells. The induction of BCL6, IL-21, and ICOS expression in Tfh cells in B Tbk1 ${ }^{-/-}$mice suggests that the lack of GC in B Tbk1 ${ }^{-1-}$ mice was not due to impaired Tfh cell formation. The $\mathrm{T}$ follicular regulatory (Tfr) cell is a new player that limits GC formation by suppressing $\mathrm{Tfh}$ cell function (Wing et al., 2017). However, the populations of Tfr cells were comparable between $\mathrm{B} \mathrm{Tbk1}^{-/-}$and the WT counterpart (Fig. $2 \mathrm{D}$ ), suggesting the lack of sustainable Tfh cells was not due to inhibition by Foxp3 ${ }^{+}$Tfr cells. The maintenance of Tfh cells is known to be dependent on constant interaction with GC $\mathrm{B}$ cells. Therefore, we investigated the costimulatory molecule expression on B cells. We found that ICOSL and CD86 expression on B cells was significantly reduced in B $\mathrm{Tbk1}^{-1-}$ mice on day 24 after infection (Fig. $2 \mathrm{E}$ ), suggesting that TBK1 sustains B-T cell interaction for Tfh cell maintenance. The increase of ICOS expression on Tfh cells in PyNL-infected B Tbk1 $1^{-/-}$mice was likely due to the higher parasitemia, because immunization-induced up-regulation of ICOS expression on Tfh cells was not higher in B Tbk1 $1^{-1-}$ mice than in the WT mice (Fig. $2 \mathrm{~F}$ ), indicating the suppressed ICOSL on B cell was not indirectly affected by ICOS expression on Tfh cells.

To understand whether the impaired GC formation in B $\mathrm{Tbk1}^{-1-}$ mice was due to an unsustainable Tfh cell population, we immunized mixed bone marrow chimeric mice containing 50:50 Tbk1 ${ }^{-1-}$ and WT B cell populations (Fig. $2 \mathrm{G}$ ). The supposed Tfh cell population can at least be maintained by WT B cells within the same mouse; yet, $\mathrm{Tbk1}^{-/-} \mathrm{B}$ cells failed to effectively differentiate into GC B cells (Fig. 2, H and I), indicating that TBK1 controls B cell-intrinsic signaling for GC B cell differentiation. Consistently, we also observed a marked reduction of ICOSL expression on the small population of $\mathrm{Tbkl}^{-/-} \mathrm{GC}$ B cells formed in the chimeric mice. Taken together, all data suggest that Tbk1deficient $\mathrm{B}$ cells were able to activate cognate $\mathrm{CD} 4 \mathrm{~T}$ cells and initiate Tfh cell differentiation; however, in return, the lack of GC formation could not sustain Tfh cell maintenance in the long term due to unsustainable ICOS-ICOSL interaction.

\section{$\mathrm{CD}^{+} \mathrm{T}$ cell-intrinsic TBK1 is dispensable for $\mathrm{Tfh}$ cell maturation}

We next sought to directly investigate whether $\mathrm{CD}^{+} \mathrm{T}$ cellintrinsic TBK1 is required for Th cell maturation and GC formation, because TBK1 was reported to be involved in the maturation of Tfh cells using adoptive transfer of $\mathrm{CD}^{+} \mathrm{T}$ cells transduced with shRNA to silence the Tbk1 gene (Pedros et al., 2016). We generated Cd4 ${ }^{\text {cre }} T b k 1^{\text {flox }}\left(\mathrm{T} \mathrm{Tbk1}^{-/-}\right)$mice in which $\mathrm{Tbk1}$ was specifically deleted in $\mathrm{CD}^{+} \mathrm{T}$ cells (Fig. $3 \mathrm{~A}$ ). We found that Tbk1-deficient $\mathrm{CD} 4^{+}$ $\mathrm{T}$ cells could differentiate into mature Tfh cells with BCL6, IL-21, and ICOS expression comparable to that of the WT counterparts in both PyNL infection and immunization models (Fig. 3, B-D). We further examined the functionality of these Tfh cells by evaluating the ability of Tbk1-deficient Tfh cells to induce GC formation in both PyNL infection and immunization models. Surprisingly, unlike the previous report that Tbk1 knockdown in $\mathrm{CD}^{+}{ }^{+} \mathrm{T}$ cells was unable to induce GC formation (Pedros et al., 2016), we could detect comparable GC B cell populations in $\mathrm{T} \mathrm{Tbk1^{-/- }}$ mice and the WT counterparts (Fig. 3, E and F). Overall, collectively, these data show that $\mathrm{B}$ cell-intrinsic but not $\mathrm{CD} 4^{+} \mathrm{T}$ cell-intrinsic TBK1 plays an important role in the regulation of GC formation.

\section{TBK1 determines B cell fate by controlling the transcriptional profile of Pre-GC}

As TBK1 phosphorylation increased in CD $38^{+}$GL7 $^{+}$Pre-GC cells compared with naive B cells (Fig. 1 A), we examined whether TBK1 is essential for B cells to proliferate and differentiate into a Pre-GC population. There was no impaired proliferation of activated B cells, as malaria-activated B cells from B Tbk1 ${ }^{-1-}$ mice had equal proliferation capacity in response to $\mathrm{CD} 40$ or IgM stimulation as the B Tbk1 ${ }^{+/+}$mice (Fig. $4 \mathrm{~A}$ ). Moreover, a substantial amount of the Pre-GC population could be detected in the spleen on day 9 after PyNL infection, regardless of the presence of TBK1 in B cells, albeit less in B Tbk1 ${ }^{-/-}$mice (Fig. 4 B), with significantly reduced IgG1 class switching (Fig. $4 \mathrm{C}$ ). To determine whether the lack of GC formation was due to impaired Pre-GC proliferation, we performed an in vivo 5-ethynyl-2'-deoxyuridine (EdU) assay; however, we did not find differences in cell cycle and proliferation between $\mathrm{Tbk1}^{-{ }^{-}}$and Tbk1 ${ }^{+/+}$Pre-GC (Fig. 4 D), nor did cell death increase in Pre-GC due to Tbk1 deficiency (Fig. 4 E).

Next, to identify the TBK1-mediated factors that determine differentiation of Pre-GC into mature GC, we sorted Pre-GC populations from B Tbk1 ${ }^{-/-}$and B $\mathrm{Tbkl}^{+/+}$mice for RNA sequencing (RNA-seq). Gene set enrichment analysis (GSEA; Subramanian et al., 2005) using hallmark gene sets from the Molecular Signatures Database (MSigDB) revealed that gene signatures highly enriched in $\mathrm{Tbkl}^{-1-}$ Pre-GC were related to Myc target genes and NF- $\mathrm{kB}$ signaling (Fig. 4 F), which are 
A
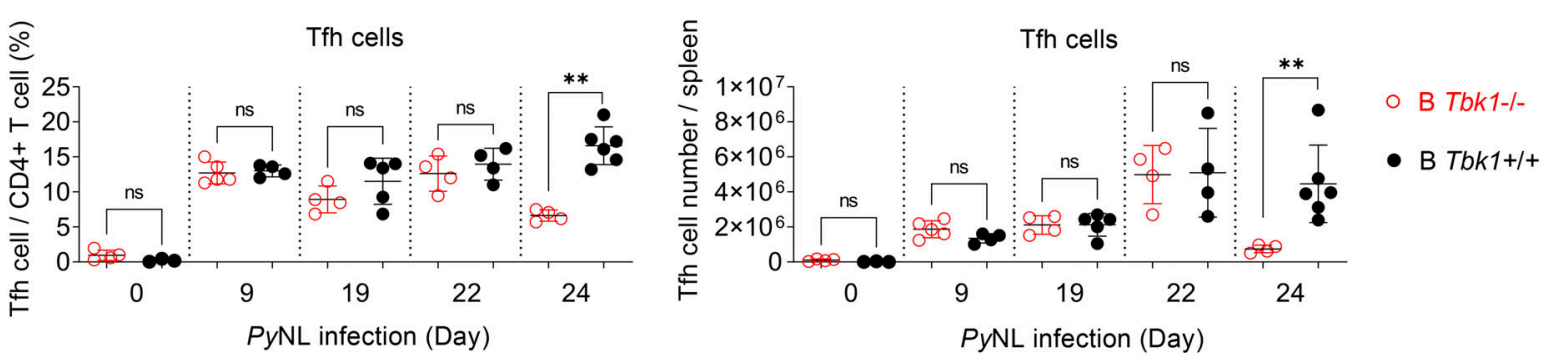

B
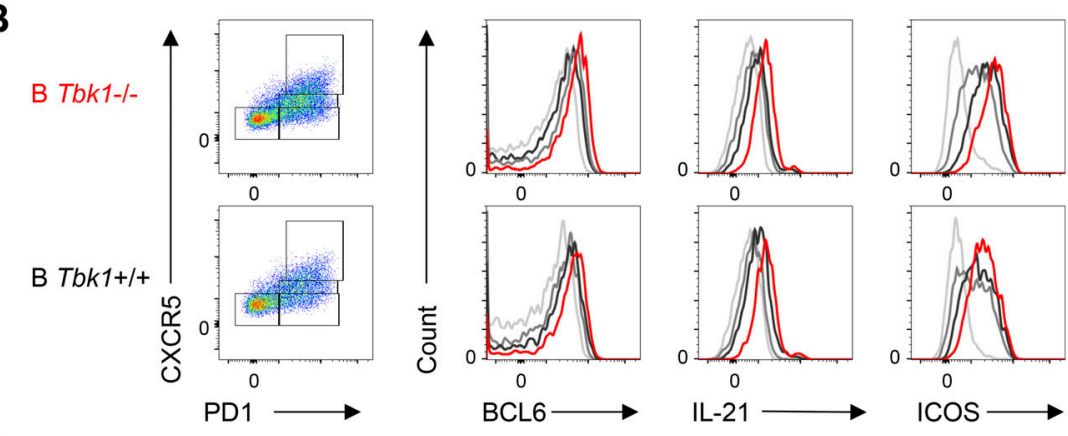

Naïve T cell

$\square$ Activated T cells

$\square$ Pre-Tfh cells

$\square$ Th cells

C

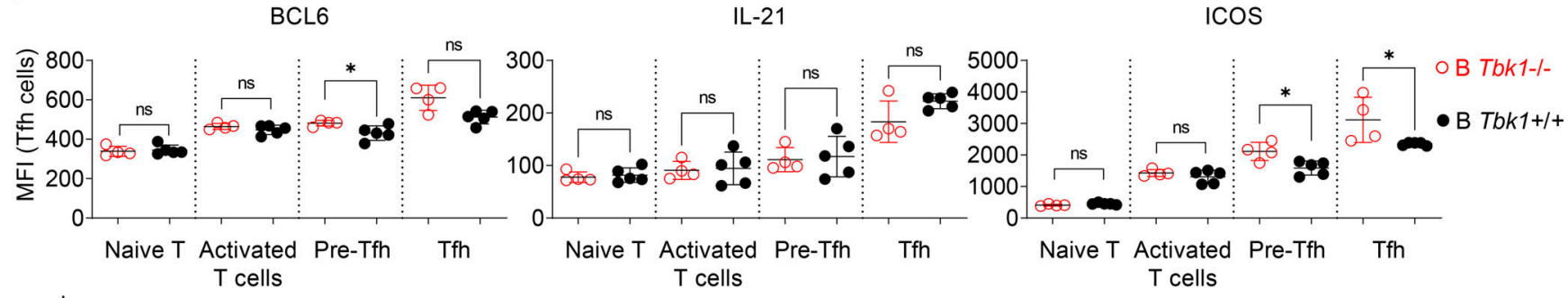

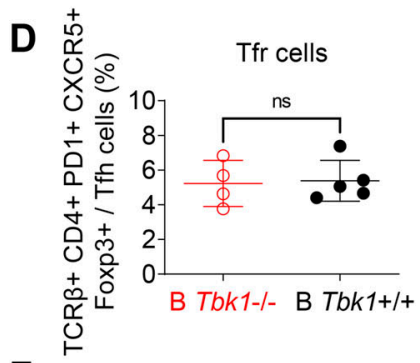

$\mathbf{F}$

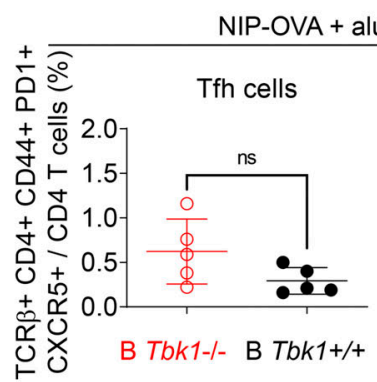

E
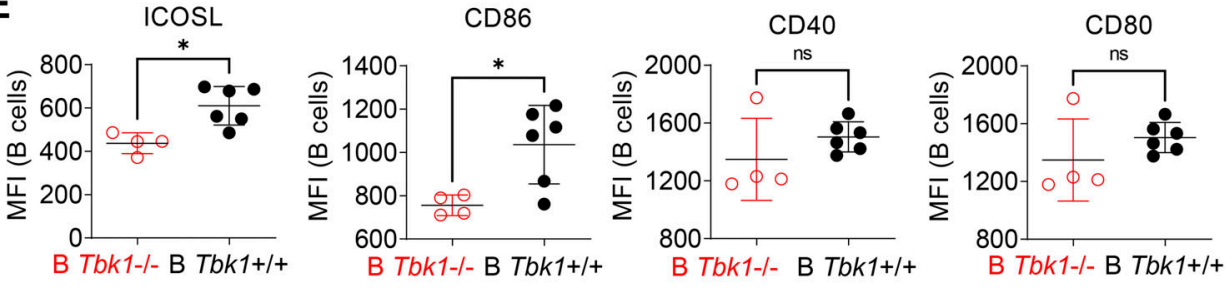

G
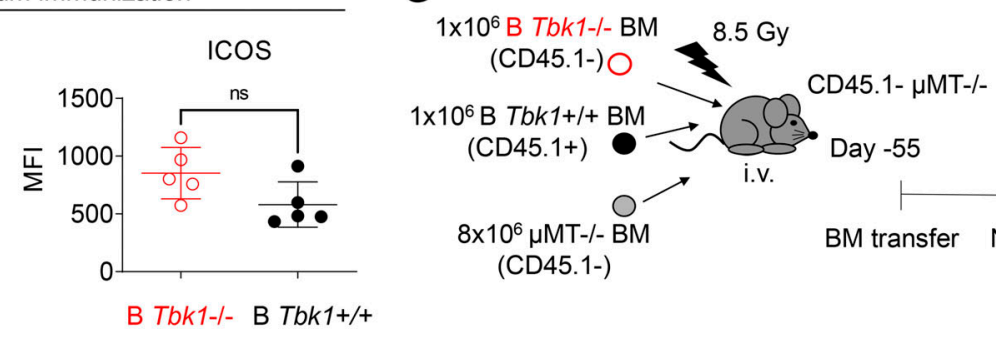

$(\mathrm{CD} 45.1+) \rightarrow$ Day -55

0

12

$8 \times 10^{6} \mu \mathrm{MT}-/-\mathrm{BM}$

BM transfer NPOVA+ alum Analysis

(CD45.1-)
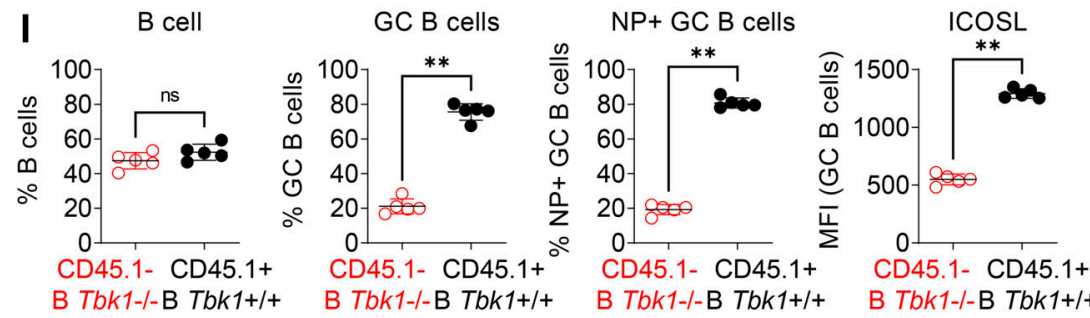

Figure 2. TBK1-deficient B cells drive Tfh cell differentiation despite the lack of GC B cells. (A) Time-course analysis of Th cell proportions and cell

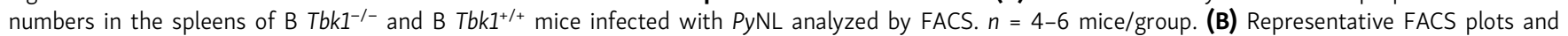


histograms of BCL6, IL-21, and ICOS expression in naive T cells (TCR $\beta^{+}$CD4 ${ }^{+}$PD1- CXCR5-), activated T cells (TCR $\beta^{+}$CD4 $4^{+}$PD1 $1^{+}$CXCR5 $5^{-}$), pre-Tfh cells (TCR $\beta^{+}$

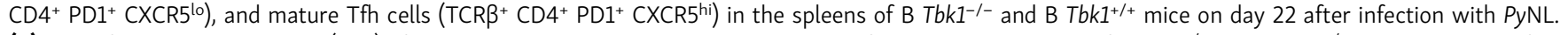

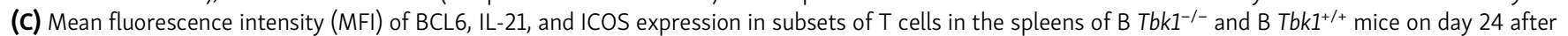

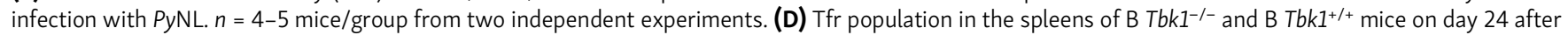
infection with PyNL. $n=4-5$ mice/group. (E) MFI of ICOSL, CD86, CD40, and CD80 expression on B cells on day 24 after infection with PyNL. $n=4-6$ mice/ group. (F) Tfh cell population and ICOS expression on Tfh cells in the dLN on day 12 after immunization with NIP-OVA and alum. $n=5$ mice/group. (G-I) Mixed bone marrow (BM) chimeric mice were immunized with NIP-OVA and alum. Schematic diagram of the experimental protocol (G), flow cytometry gating

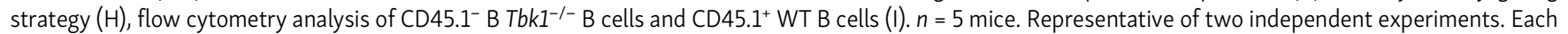
dot represents an individual mouse. Data are from four experiments $(A)$ or are representative of two experiments $(B-I)$. Data are shown as mean $\pm S D$. ${ }^{*}, P<$ $0.05 ;{ }^{* *}, \mathrm{P}<0.01$; Mann-Whitney $t$ test $(\mathrm{A}, \mathrm{C}-\mathrm{F}$, and $\mathrm{I})$.

signaling downstream of $\mathrm{BCR}$ and $\mathrm{CD} 40$ activation. Of the 588 significantly up-regulated genes and 557 down-regulated genes in B Tbk1 ${ }^{-/-}$Pre-GC cells compared with B Tbk1 ${ }^{+/+}$Pre-GC, we focused on those that were up-regulated or down-regulated by 1.33 -fold (adjusted $\mathrm{P}<0.05$ ), which were 131 genes and 147 genes, respectively (Fig. $4 \mathrm{G}$ ). Gene ontology (GO) analysis for biological process consistently showed that most up-regulated genes were related to regulation of signal transduction, including Nfkbid, Nfkbia, Ebi3, Irf4, and $M y c$, which are associated with CD40 and BCR signaling (Fig. $4 \mathrm{H}$ and Fig. S4 A). Therefore, we further analyzed gene signatures of BCR and CD40 signaling (Victora et al., 2010), and we found significant up-regulation of CD40- and BCR-induced genes in Tbk1-deficient Pre-GC (Fig. 4 I and Fig. $\mathrm{S} 4 \mathrm{~B}$ ), suggesting that TBK1 acts as a negative regulator of CD40 and BCR signaling in Pre-GC. A Myc ${ }^{+}$Pre-GC-specific gene signature (Calado et al., 2012) further confirmed that TBK1 negatively regulates Myc-related genes (Fig. 4 I). Consistent with the phenotype of previously reported $\mathrm{Myc}^{+}$Pre-GC (Calado et al., 2012), we found that Tbk1-deficient Pre-GC had increased Nfkbia and Nfkbid expression indicative of enhanced NF- $\mathrm{kB}$ activation. Notably, enhanced $M y c$ and Irf4 expression in Pre-GC was shown to suppress GC-related genes (Dominguez-Sola et al., 2012). Collectively, these findings suggest that TBK1 regulates Myc and NF- $\mathrm{kB}$ signaling via $\mathrm{CD} 40$ and $\mathrm{BCR}$ signaling for $\mathrm{GC}$ fate decision.

\section{TBK1 negatively regulates IRF4 in Pre-GC}

IRF4 is an early transient transcription factor induced by CD40 signaling that is essential for the transcriptional regulation of GC genes such as Bcl6 (Ochiai et al., 2013). However, IRF4 has been shown to act as a double-edged sword with opposing roles in the regulation of GC differentiation, depending on its expression levels at different stages of GC differentiation (Zhang et al., 2017). Although IRF4 drives the expression of Bcl6, sustained up-regulation of IRF4 expression in turn suppresses the transcription of Bcl6 (Saito et al., 2007). Consistent with our RNA-seq data (Table S1), we additionally found that Tbk1-deficient Pre-GC had increased expression of IRF4 and decreased BCL6 by flow cytometric analysis (Fig. 5, A and B). Tbk1-deficient B cells preferentially differentiated into a IRF4 ${ }^{+} \mathrm{Bcl}^{-}$population, in contrast to the increase of the $\mathrm{Bcl6}^{+}$IRF4- Pre-GC population in B $\mathrm{Tbk1}^{+/+}$mice (Fig. $5 \mathrm{C}$ ). The decreased ratio of BCL6/IRF4 expression in Pre-GC (Fig. 5 D) indicates that Tbk1-deficient Pre-GC has a lower potential to further differentiate into mature GC $\mathrm{B}$ cells. Indeed, the population of BCL6 ${ }^{+} \mathrm{B}$ cells was consistently suppressed in $\mathrm{B} \mathrm{Tbk1^{-1- }}$ mice, while $\mathrm{BCL}^{+} \mathrm{B}$ cells expanded ninefold and differentiated into GC B cell in B $\mathrm{Tbkl}^{+/+}$mice on day 24 after infection (Fig. 5 E). The Pre-GC population has been shown to have the potential to either differentiate into GC or GCindependent plasmablast/memory B cells (Taylor et al., 2012). Notably, IRF4 is also a transcription factor that drives the gene expression of Prdml that encodes BLIMP-1, the master regulator of plasmablast differentiation (Klein et al., 2006). Our RNA-seq data also showed that Prdml gene expression was significantly up-regulated in Tbk1-deficient Pre-GC (Table S1), indicating that the differentiation commitment of this population was skewed to a plasmablast fate instead of a GC B cell fate. Consistently, with the increased Prdml expression in Tbk1-deficient Pre-GC, the population of $\mathrm{CD} 138^{+}$ASCs was significantly higher in B $\mathrm{Tbk1}^{-/-}$mice at the acute phase of infection (Fig. $5 \mathrm{~F}$ ). These findings strongly support that TBK1 dictates the fate of the PreGC population to predominantly differentiate into GC by controlling the expression of IRF4.

\section{TBK1 limits the activation of CD40 signaling in B cells via TNF receptor-associated factor 2 (TRAF2)}

CD40 stimulation of B cells induces both canonical and noncanonical NF- $\kappa B$ signaling with differential roles in B cell survival, proliferation, isotype switching, and differentiation fate (Zarnegar et al., 2004; Heise et al., 2014). IRF4 is a downstream target of NF- $\mathrm{BB}$ upon CD40 stimulation in B cells (De Silva et al., 2016). Indeed, we found that CD40 stimulation, but not BCR stimulation, strongly induced IRF4 expression in naive B cells (Fig. $5 \mathrm{G}$ ). Furthermore, noncanonical NF-kB signaling was enhanced upon CD40 stimulation (Fig. S5). To examine whether TBK1 modulates IRF4 expression via NF- $\kappa$ B in Pre-GC, we examined the expression of noncanonical NF- $\kappa B$ molecules RelB

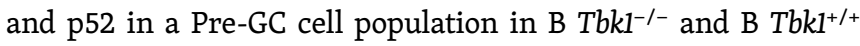
mice. We found that the expression of RelB and p52 was significantly higher in Tbk1-deficient Pre-GC than in the WT Pre-GC (Fig. $5 \mathrm{H}$ ). Collectively, our findings suggest that TBK1 negatively regulates $C D 40$ signaling via noncanonical NF- $\kappa B$ that skews the balance of IRF4/BCL6 to promote GC formation.

We next sought the role of CD40 stimulation on the induction of TBK1 phosphorylation; therefore, we stimulated purified naive B cells with anti-CD40 and then performed Western blot analysis. To our surprise, we found that CD40 stimulation downregulated TBK1 phosphorylation as early as $10 \mathrm{~min}$ after stimulation (Fig. $5 \mathrm{I}$ ). This prompted us to hypothesize that TBK1 limits the activation of CD40 signaling in steady state to prevent CD40 overactivation spontaneously in the absence of CD4OL and that a reduced phosphorylation level of TBK1, but not complete 
A
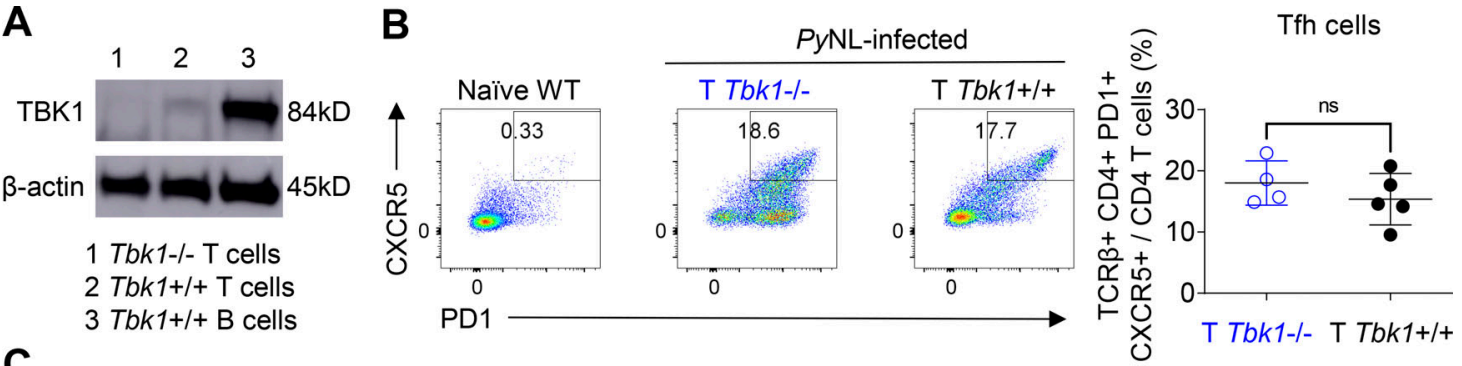

C
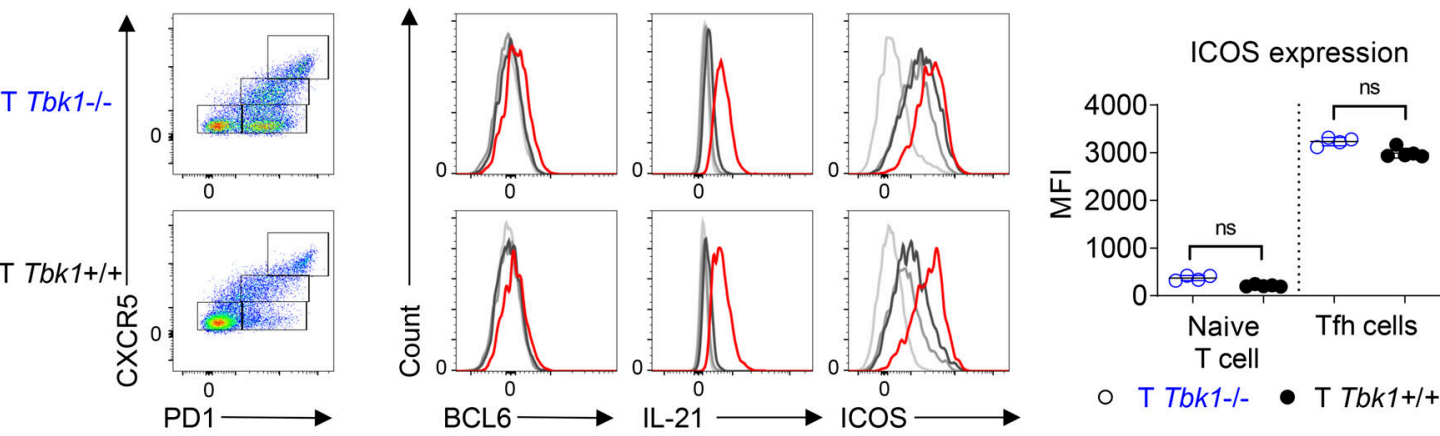

Naive T cell $\square$ Activated T cells $\square$ Pre-Tfh cells $\square$ Tfh cells

D
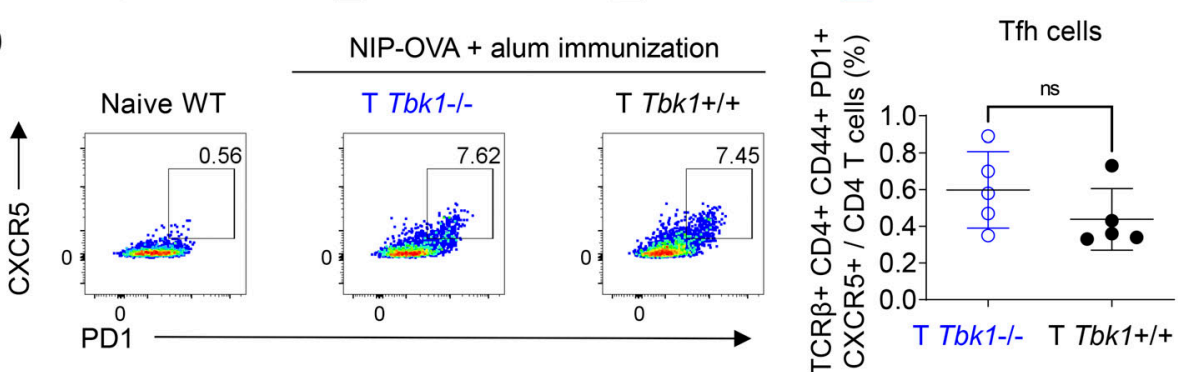

E
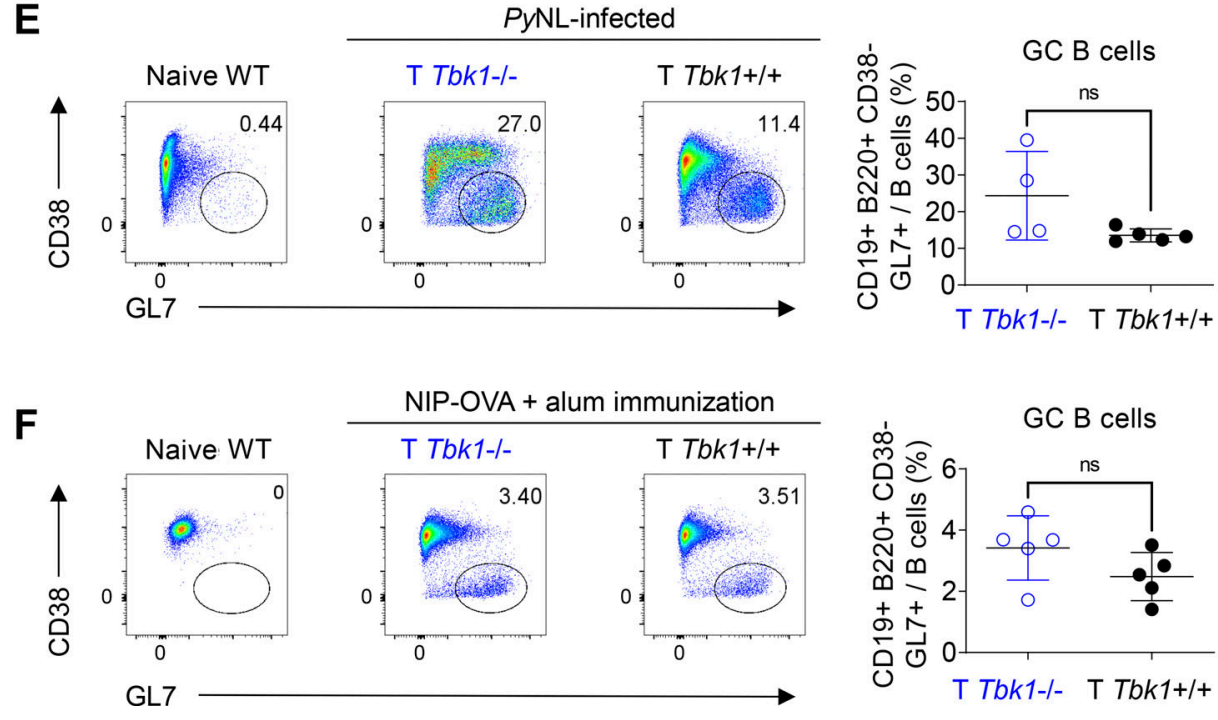

Figure 3. CD4 $^{+} T$ cell-intrinsic TBK1 is dispensable for $T$ fh cell maturation. (A) Depletion efficiency of $T b k 1$ in splenic $C D 4^{+} T$ cells of $C d 4^{\text {cre }} T b k 1^{f / f}$ mice $(T$

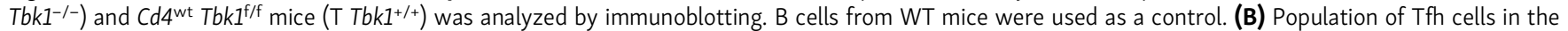

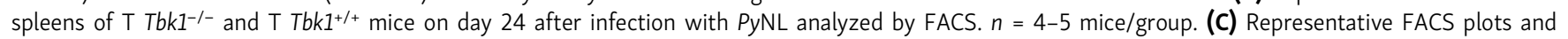
histograms of BCL6, IL-21, and ICOS expression in naive T cells, activated T cells, pre-Tfh cells, and mature Tfh cells in the spleens of T Tbk1 $1^{-/-}$and T Tbk1 $1^{+/+}$ mice on day 24 after infection with PyNL. $n=4-5$ mice/group. MFI, mean fluorescence intensity. (D) Population of Tfh cells in the spleens of T Tbk1 ${ }^{-/-}$and T $\mathrm{Tbk1}^{+/+}$mice on day 12 after immunization with NIP-OVA with alum. $n=5$ mice/group. (E) GC population in the spleens of T Tbk $1^{-/-}$and T Tbk1 ${ }^{+/+}$mice on day 24 after infection with PyNL. $n=4-5$ mice/group. (F) GC population in the spleens of T Tbk1 $1^{-/-}$and T Tbk1 $1^{+/+}$mice on day 12 after immunization with NIP-OVA with alum. $N=5$ mice/group. Each dot represents an individual mouse. Data are representative of two independent experiments $(A-F)$. Data are shown as mean \pm SD. Mann-Whitney $t$ test $(B-F)$. Source data are available for this figure: SourceData F3. 
A

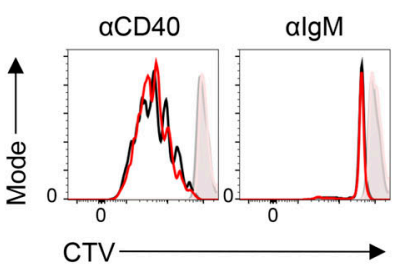

B Tbk1-/- Unstimulated

$\square$ B Tbk1-/- Stimulated

B Tbk1+/+ Unstimulated

$\square$ B Tbk1+/+ Stimulated

B
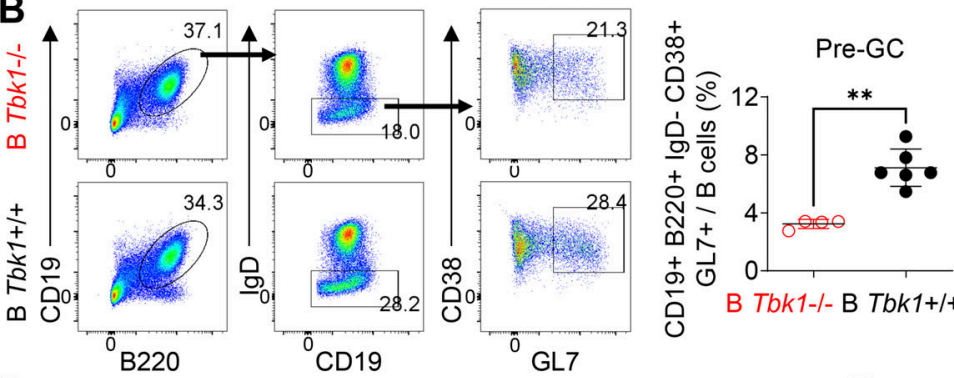

Expansion index (activated B cells)
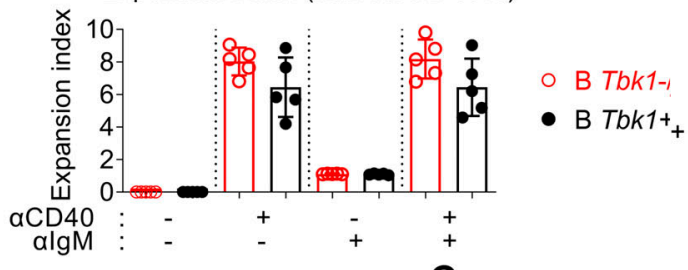
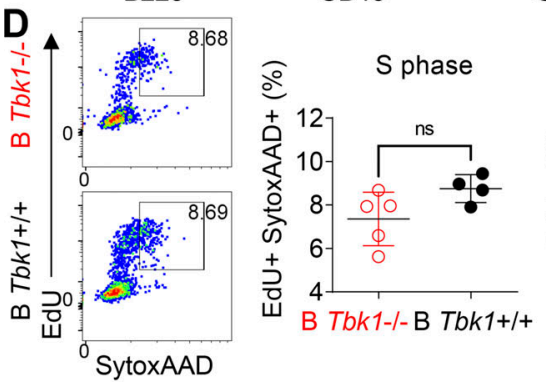

EdU+ Pre-GC
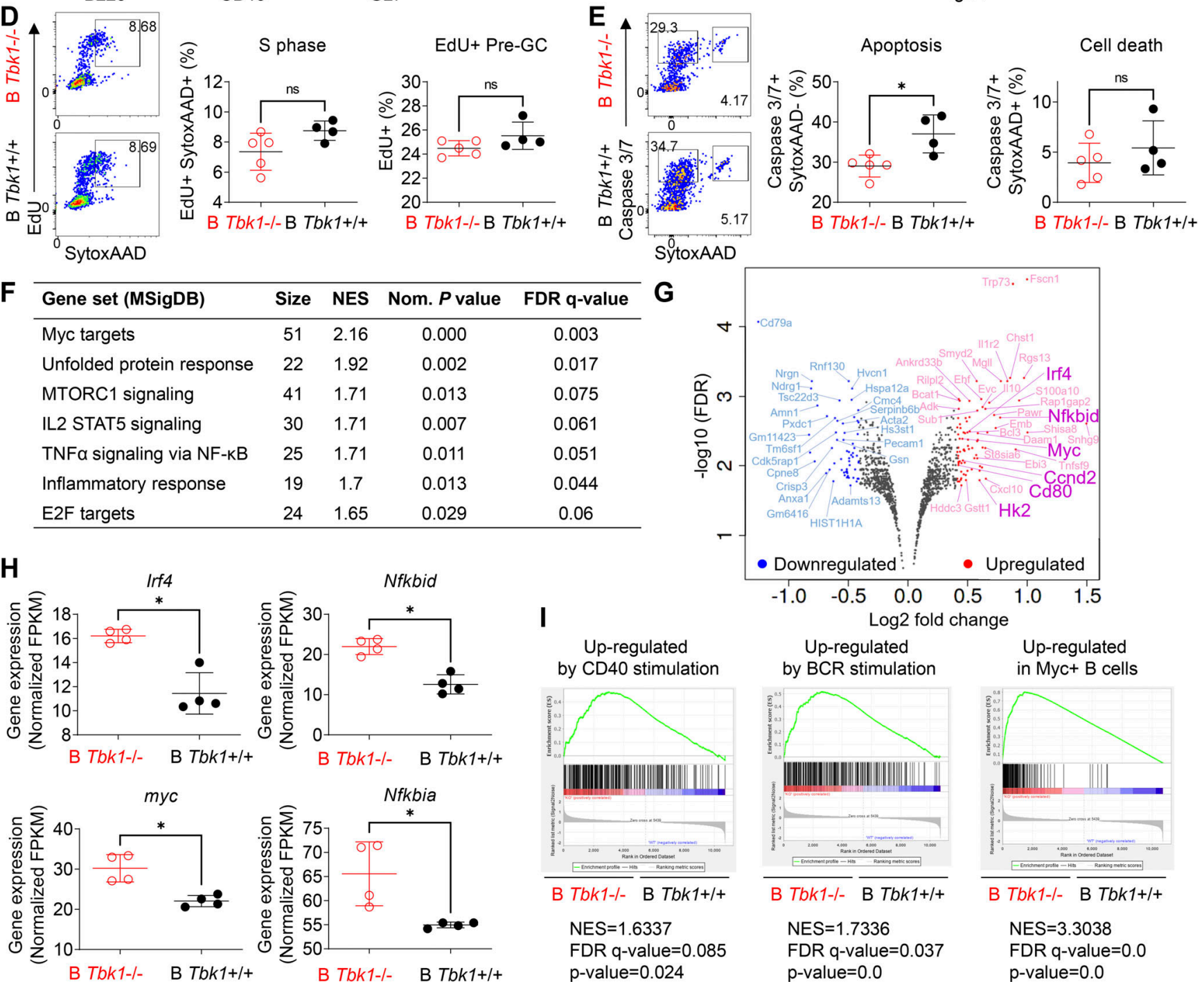

I
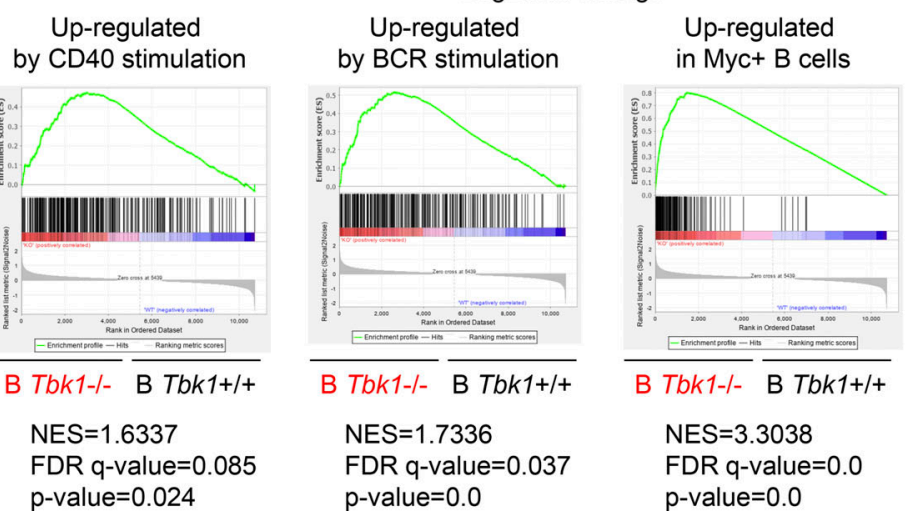

Figure 4. TBK1 deficiency alters the gene expression in Pre-GC. (A) Representative histograms and expansion index of CTV-stained splenic B cells of day

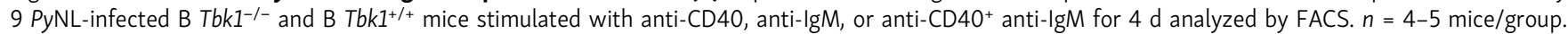

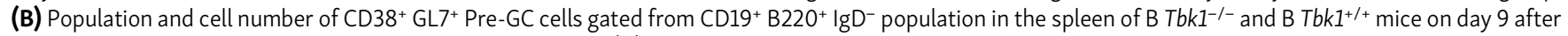

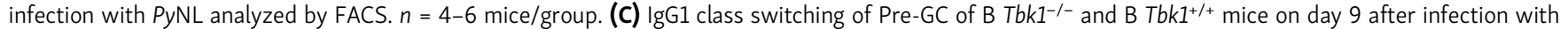
PyNL. $n=4-6$ mice/group. (D) Cell cycle analysis of Pre-GC on day 9 after infection with PyNL. $n=4-5$ mice/group. (E) Apoptotic cell death analysis of Pre-GC on day 9 after infection with PyNL. $n=4-5$ mice/group. (F) Pre-GC isolated from day 9 after infection with PyNL analyzed by RNA-seq. $n=4$ mice/group. Gene 
sets enriched for DEGs between B Tbk1 $1^{-/-}$Pre-GC and B Tbk1 ${ }^{+/+}$Pre-GC analyzed by GSEA using gene signatures from MSigDB Hallmark (false discovery rate [FDR] q value <0.25\%; P< 0.05). NES, normalized enrichment score. (G) Volcano plot of DEGs (1.33-fold; P< 0.05$)$ between B Tbk1 ${ }^{-/-}$Pre-GC and B Tbk1 ${ }^{+/+}$PreGC isolated from day 9 after infection with PyNL analyzed by RNA-seq. $n=4$ mice/group. (H) Gene expression of Irf4, myc, Nfkbid, and Nfkbia presented as fragments per kilobase of exon per million reads mapped (FPKM) values in RNA-seq of B Tbk1 ${ }^{-/-}$Pre-GC and B Tbk1 $1^{+/+}$Pre-GC. (I) Enrichment of genes up-

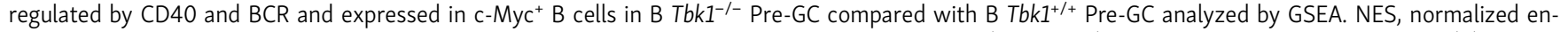
richment score. Each dot represents data from an individual mouse. Data are representative of two ( $A$ and $C-E)$ or three independent experiments (B) or from one experiment $(\mathrm{F}-\mathrm{I})$. Data are shown as mean $\pm \mathrm{SD} .{ }^{*}, \mathrm{P}<0.05 ;{ }^{* *}, \mathrm{P}<0.01$; Mann-Whitney $t$ test $(\mathrm{A}-\mathrm{E}$ and $\mathrm{H})$. AAD, SYTOX AADvanced.

abrogation of TBK1, may be required to allow optimal CD40 activation. TRAF2 is a molecule downstream of CD40 that regulates noncanonical NF- $\kappa$ B. Therefore, we examined the phosphorylation of TRAF2 at serine 11 upon CD40 stimulation and found that phosphorylation of TRAF2 S11 was partially dependent on TBK1 (Fig. 5 I). Collectively, our findings suggest that TBK1 negatively regulates $C D 40$ signaling to skew the balance of IRF4/BCL6 to promote GC formation via TRAF2 phosphorylation and noncanonical NF- $\mathrm{BB}$ signaling.

\section{TBK1 fine-tunes CD40 together with BCR signaling in Pre-CC}

The alteration of $C D 40$ and $B C R$ signaling as naive $B$ cells differentiate into GC suggests that fine tuning of CD40 and BCR signaling may be important to determine the differentiation fate of Pre-GC (Luo et al., 2018, 2019). Therefore, we sought to examine the role of TBK1 in the regulation of CD40 and BCR signaling, specifically in Pre-GC. Due to the difficulty of isolating the small population of Pre-GC for ex vivo stimulation, we stimulated splenocytes from PyNL-infected mice on day 9 and gated on the $\mathrm{GL7}^{+} \mathrm{B}$ cells as Pre-GC and the GL7- B cells as non-Pre-GC control (Fig. 6 A). Unlike in naive B cells (Fig. 5 G), $B C R$ activation alone strongly up-regulated IRF4 expression in $\mathrm{GL7}^{+}$Pre-GC, and it was further enhanced by CD40 costimulation (Fig. $6 \mathrm{~B}$ ). We also found that the synergistic effect of BCR and CD40 stimulation on IRF4 is boosted in Tbk1-deficient GL7 $^{+}$Pre-GC and GL7- non-Pre-GC (Fig. 6 B). This finding supports our RNA-seq data showing that TBK1 negatively regulates IRF4 via both CD40 and BCR signaling in Pre-GC. Notably, IRF4 and c-Myc expression was slightly but significantly higher in unstimulated Tbk1-deficient Pre-GC and was enhanced by CD40 and BCR costimulation (Fig. $6 \mathrm{C}$ ). Although BCR stimulation is a strong inducer of c-Myc expression, we found that CD40 stimulation alone, but not BCR stimulation, strongly enhanced c-Myc expression in Pre-GC. CD40 stimulation further augmented c-Myc expression in Tbk1-deficient Pre-GC (Fig. 6 C). This finding indicates that the dynamics of $\mathrm{CD} 40$ and BCR signaling in Pre-GC were tightly regulated by TBK1.

AKT is a signaling molecule downstream of BCR activation that plays an important role in GC formation (Zhu et al., 2019). $B C R$ activation in naive $B$ cells induces AKT phosphorylation at the S473 hydrophobic motif by mammalian target of rapamycin complex 2 (mTORC2). However, strong AKT phosphorylation at the T308 activation loop by PDK1 in GC B cells was shown to inhibit AKT phosphorylation at S473 (Luo et al., 2019). TBK1 has been shown to phosphorylate AKT at S473 and T308 sites independent of mTORC2 and PDK1, depending on the stimulus and cell types (Ou et al., 2011; Xie et al., 2011); however, the involvement of TBK1 in AKT phosphorylation in Pre-GC B cells is unknown. We examined AKT phosphorylation in Pre-GC B cells from $P y$ NL-infected mice on day 9 and found that Tbk1 deficiency significantly enhanced phosphorylated AKT (pAKT) at T308 but only slightly at S473 (Fig. 6 D). Collectively, these data suggest that TBK1 acts as a limiting factor to regulate CD40 and BCR signaling in Pre-GC through the regulation of c-Myc, IRF4, and AKT for GC B cell differentiation.

\section{TBK1 is essential for long-lasting protective humoral immunity} While GC formation gives rise to affinity-matured memory B cells for long-term protection from infection, memory B cells could be generated in the absence of GC (Kaji et al., 2012; Taylor et al., 2012). To determine the effect of the lack of TBK1 in B cells on memory B cells, we treated both B Tbk1 ${ }^{-/-}$and WT mice with hydroxychloroquine (HCQ) antimalarial daily when they reached the peak parasitemia on day 15 after infection, and we reinfected them with $P y \mathrm{NL}$ after they had fully recovered from the primary infection (Fig. $7 \mathrm{~A}$ ). We found that B Tbk1 ${ }^{-/-}$mice were fully susceptible to reinfection, while WT controls were protected (Fig. 7 B). We examined GC formation and the generation of affinity-matured memory B cells identified by CD73 expression, which correlates with somatic hypermutation (Anderson et al., 2007). While GC was not formed in B Tbk1 ${ }^{-1-}$ mice (Fig. 7 C), CD73 expression was up-regulated on $\mathrm{IgGl}^{+}$ memory B cells in WT mice, but not in B Tbk1 ${ }^{-/}$mice (Fig. $7 \mathrm{D}$ ). Moreover, $\mathrm{B} \mathrm{Tbk1^{-1- }}$ mice had significantly fewer IgG1 ${ }^{+}$memory B cells (Fig. 7 E). This suggests that TBK1 is crucial for the generation of affinity-matured IgG $1^{+}$memory B cells through GC reaction. Notably, PyNL infection mainly induced $\mathrm{IgGl}^{+} \mathrm{GC}$ B cells, while IgG $2 \mathrm{c}^{+} \mathrm{GC}$ B cells were hardly detectable (Fig. $7 \mathrm{~F}$ ), suggesting that IgG1 ${ }^{+}$memory $B$ cells were mostly derived from $\mathrm{GC}$, while IgG2 $\mathrm{c}^{+}$memory B cells were of $\mathrm{EF}$ origin. Therefore, CD73 expression on IgG2 $\mathrm{c}^{+}$memory $\mathrm{B}$ cells was up-regulated in neither WT nor B Tbk1 ${ }^{-/-}$mice (Fig. 7 D). Even though B Tbk1 ${ }^{-1-}$ mice had increased IgG2 $\mathrm{c}^{+}$memory B cells compared with WT mice and were capable of producing IgG2c and IgM antibodies upon reinfection (Fig. $7 \mathrm{G}$ ), B Tbk1 ${ }^{-/-}$mice were still susceptible to reinfection due to the lack of IgG1 and perhaps IgG3 antibodies, suggesting the importance of GC-derived memory B cells to produce affinity-matured antibodies. Taken together, these findings clearly reveal the importance of TBK1 for the generation of long-lasting and high-quality memory B cells through GC formation, which is important for sterile immunity.

\section{Discussion}

$B$ cells rely on various extrinsic signals from $T$ cells and follicular dendritic cells, as well as cell-intrinsic signals, to determine their fate of differentiation (Cyster and Allen, 2019). Here, we identified a novel role of $B$ cell-intrinsic TBK1 as a determining factor 
A

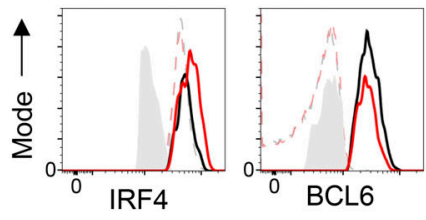

B Tbk1-l- GL7+ 1 B Tbk1-/- GL7-

B Tbk1+/+ GL7+ 1 B Tbk1+/+ GL7-

FMO control

B
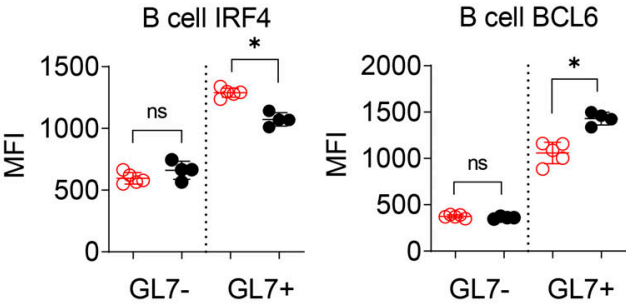

C

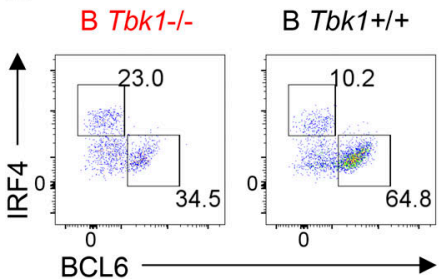

D

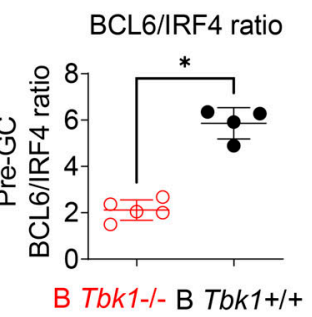

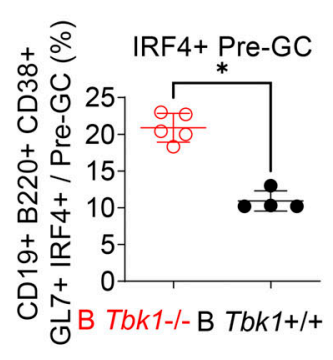
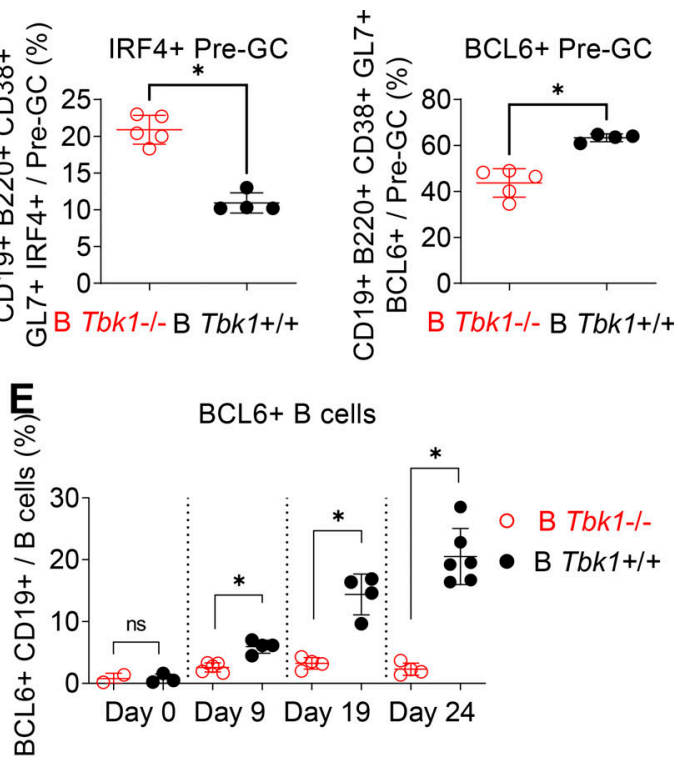

$\mathbf{F}$
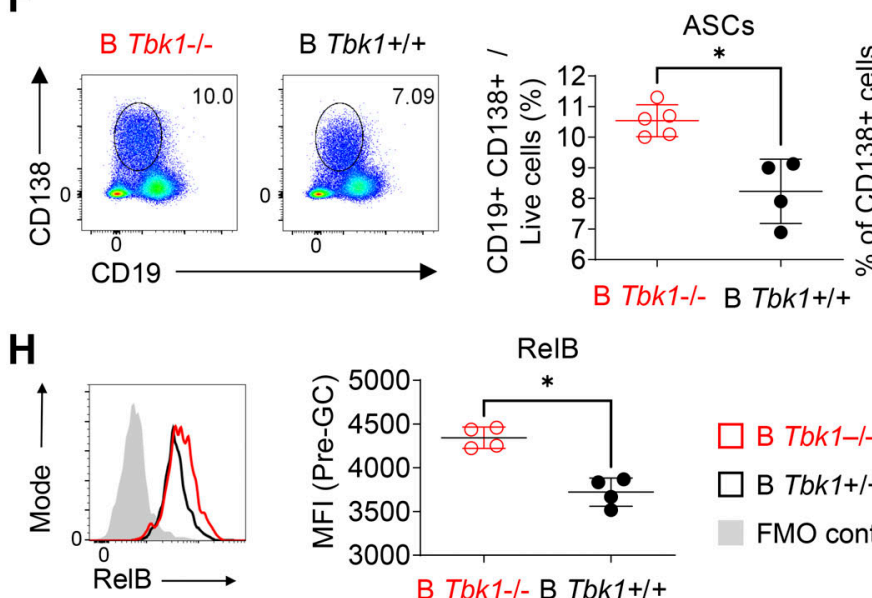$$
\text { B }
$$

B Tbk1-/- B Tbk1+/+

RelB
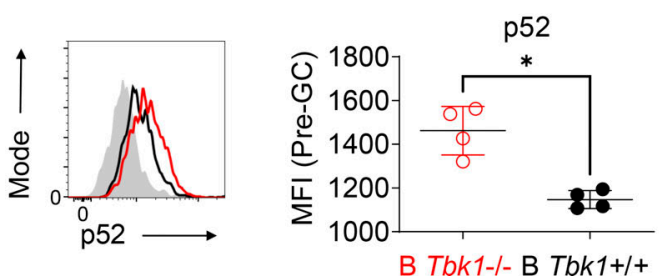

G IRF4 (Naive B cells)

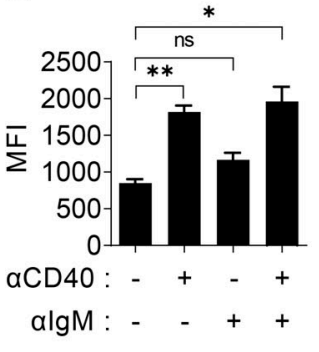

Figure 5. TBK1 negatively regulates IRF4 by limiting CD40 signaling in Pre-GC. (A and B) Representative histograms (A) and mean fluorescence intensity

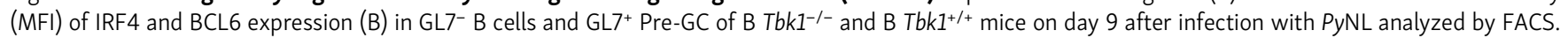
FMO, fluorescence minus one control. $n=4-5$ mice/group. (C) Representative FACS plots and proportion of IRF4+ Pre-GC and BCL6+ Pre-GC populations in the

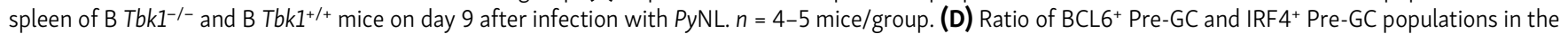
spleen on day 9 after infection with PyNL. $n=4-5$ mice/group, representative of two independent experiments. (E) Time-course analysis of BCL6 $6^{+} B$ cell

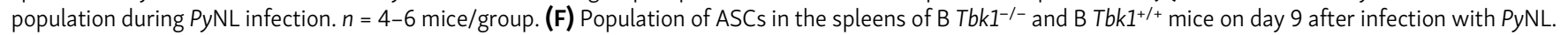
$n=4-5$ mice/group. (G) IRF4 expression in WT naive B cells stimulated for $16 \mathrm{~h}$ with $10 \mu \mathrm{g} / \mathrm{ml}$ anti-CD40 and/or with anti-lgM analyzed by FACS. $n=3$ mice.

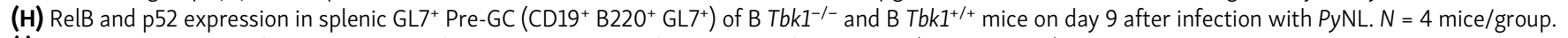
(I) Immunoblot analysis of the time course of in vitro stimulation of naive B cells from B Tbk $1^{-/-}$and B Tbk $1^{1 /+}$ mice with $1 \mu \mathrm{g} / \mathrm{ml}$ anti-CD40. Each dot represents data from an individual mouse. Data are representative of two independent experiments ( $A-D$ and $F-I$ ) or from three independent experiments ( $E$ ). Data are shown as mean $\pm \mathrm{SD} .{ }^{*}, \mathrm{P}<0.05 ;{ }^{* *}, \mathrm{P}<0.01$; Mann-Whitney $t$ test $(\mathrm{B}-\mathrm{F}$ and $\mathrm{H})$ or unpaired Student's $t$ test $(\mathrm{G})$. Source data are available for this figure: SourceData F5. 


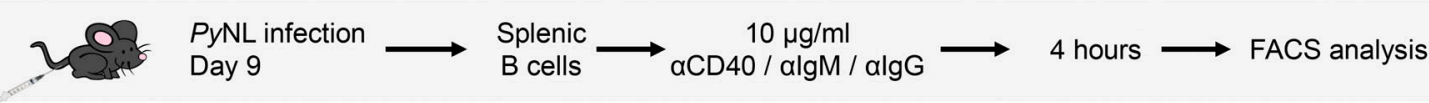

B

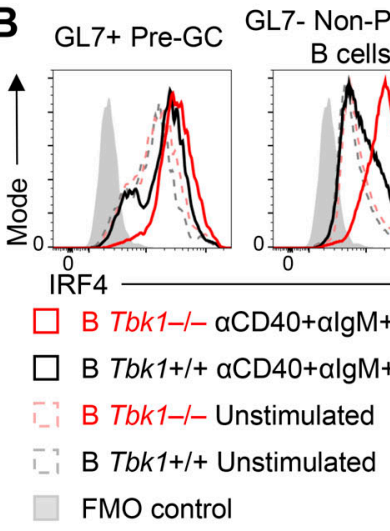

C

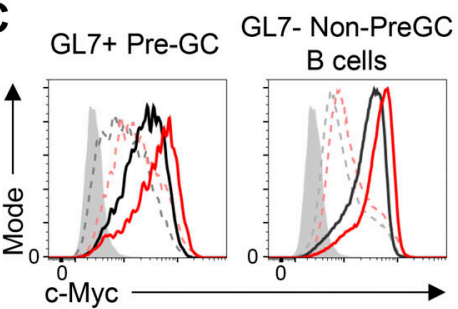

GL7+ B cells (Pre-GC)

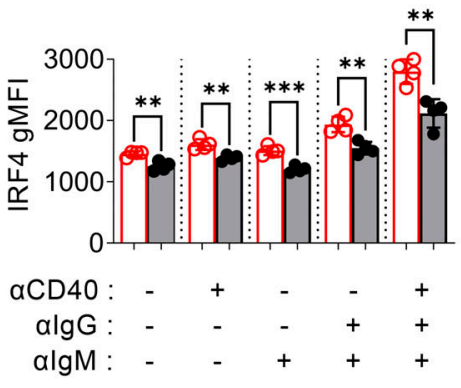

o B Tbk1-1- $\quad$ B Tbk1+/+

GL7+ B cells (Pre-GC)

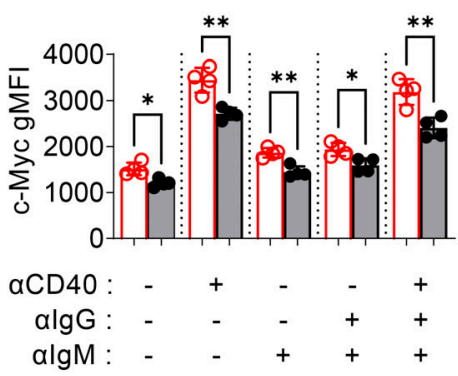

GL7- B cells (Non-PreGC)

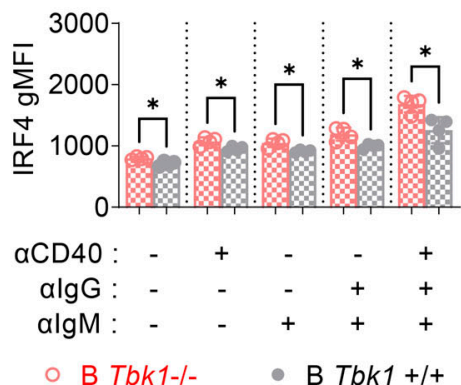

GL7- B cells (Non-PreGC)

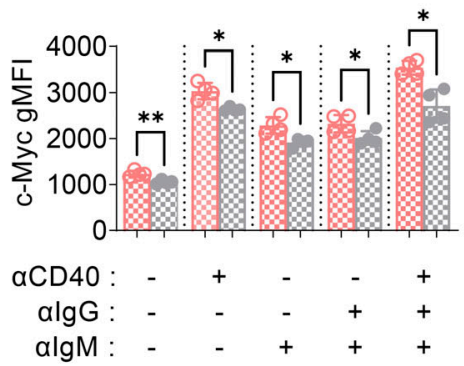

D
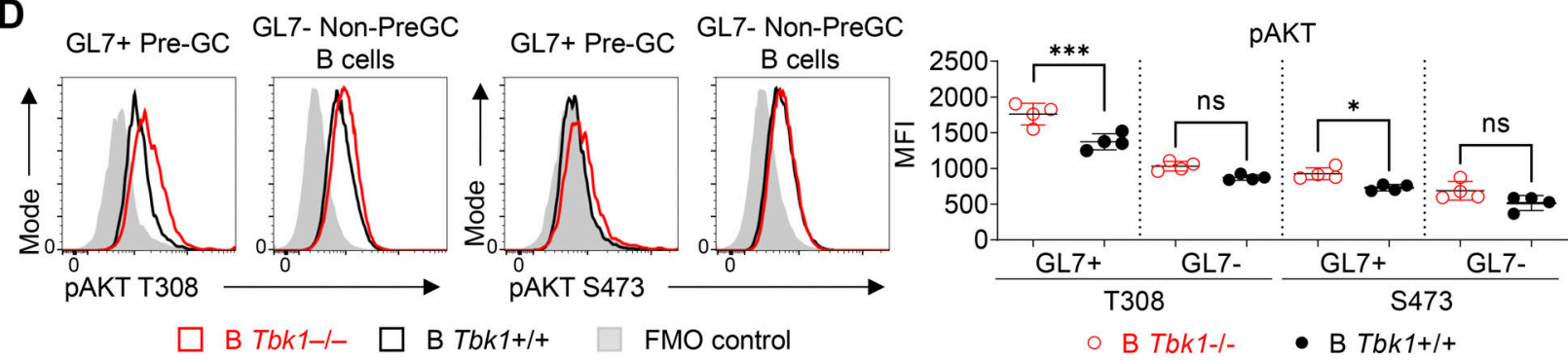

Figure 6. TBK1 is a limiting factor that fine tunes CD40 and BCR signaling in Pre-GC. (A) Schematic diagram of ex vivo splenic B cells isolated from day

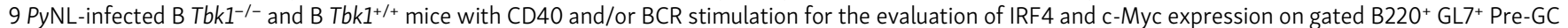
and B220+ GL7- non-Pre-GC B cell population by FACS. (B and C) Representative histograms and graphs showing IRF4 expression (B) and c-Myc expression (C) of GL7+ Pre-GC and GL7- non-Pre-GC upon CD40 and/or BCR stimulation. $n=4$ mice/group. (D) Representative histograms and graph showing AKT phosphorylation at S473 and T308 on Pre-GC cells on day 9 after infection with PyNL. $n=4$ mice/group. Each dot represents data from an individual mouse. Data are representative of two independent experiments (A-D). Data are shown as mean $\pm \mathrm{SD}$. ${ }^{*}, \mathrm{P}<0.05 ;{ }^{* *}, \mathrm{P}<0.01$; ${ }^{* * *}, \mathrm{P}<0.001$; one-way ANOVA (B and C), Mann-Whitney $t$ test (D). gMFI, geometric mean fluorescence intensity.

for GC commitment, and we also confirmed that TBK1 in CD4 ${ }^{+}$ $\mathrm{T}$ cells plays a limited role in GC formation. Tbkl-deficient B cells can differentiate up to the Pre-GC stage and drive Tfh cell differentiation; however, they failed to further differentiate into GC. Instead, Tbk1-deficient Pre-GC committed to a GCindependent fate to differentiate into plasmablasts and memory B cells, but with lack of affinity maturation, and therefore they could not protect the host from an otherwise nonlethal malaria infection. Mechanistically, TBK1 negatively regulates CD40 and BCR signaling to down-regulate IRF4 and c-Myc expression in Pre-GC that leads to the up-regulation of the GC master regulator, BCL6. We further showed that B cell-intrinsic TBK1 fine tunes both CD40 and BCR signaling by negatively regulating noncanonical NF- $\kappa$ B, TRAF2, and AKT T308 phosphorylation and thereby synergistically controls IRF4 expression in Pre-GC.

Although known for its role in phosphorylating molecules involved in nucleic acid sensing to produce IFN-I, TBK1 is a pleiotropic kinase that is involved in the regulation of various signaling pathways (Louis et al., 2018). The lack of a consensus binding sequence gave rise to the hypothesis that the involvement of TBK1 depends on its cellular location and abundance (Helgason et al., 2013). This hypothesis is supported by a recent study showing the differential localization of phospho-TBK1 in response to the same stimulant in a cell type-specific manner (Suzuki et al., 2013). Therefore, we would expect TBK1 to have 

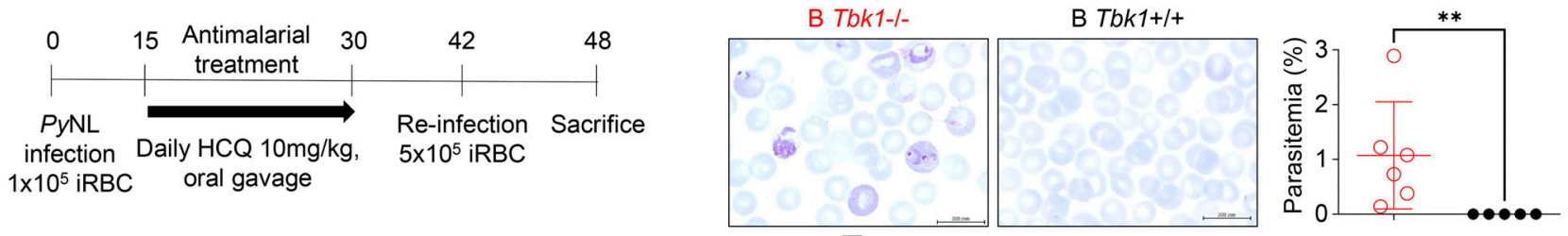

C
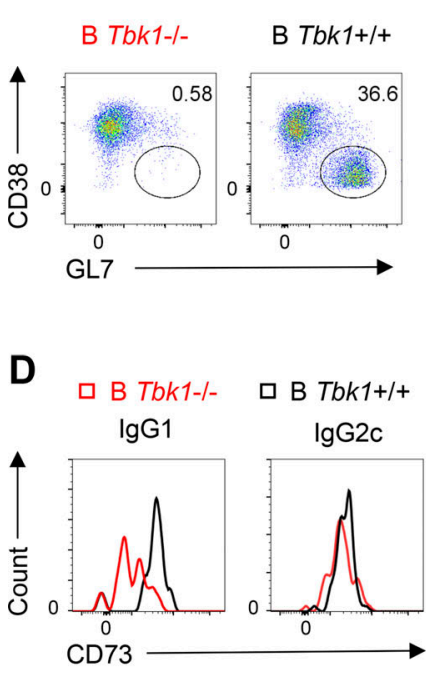

G

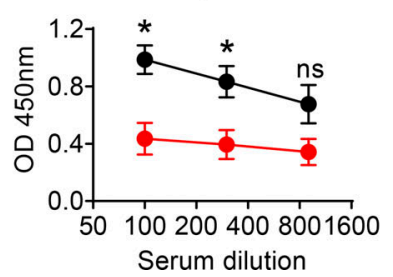

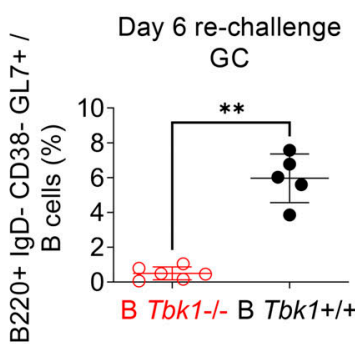

CD73
E

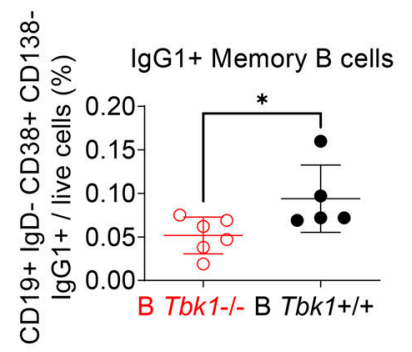

B Tbk1-l- B Tbk1+/+

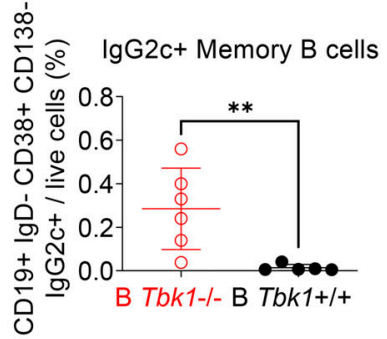

$F$

(IgG1 Memory B cells) (IgG2c Memory B cells)
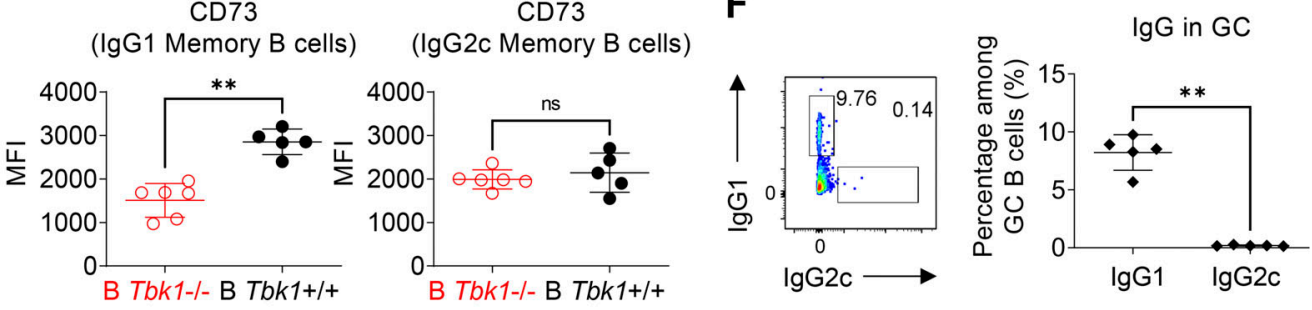

$\lg \mathrm{G} 3$
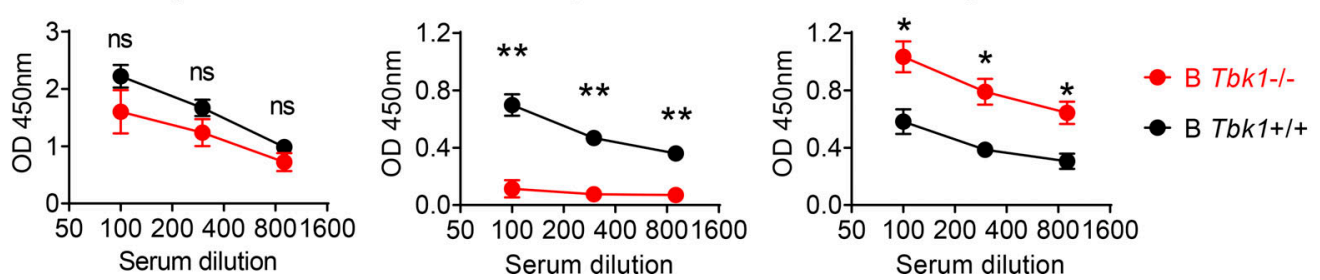

Figure 7. B cell-intrinsic TBK1 deficiency impairs immunity to reinfection. (A) Schematic diagram of PyNL infection, treatment, and reinfection for the

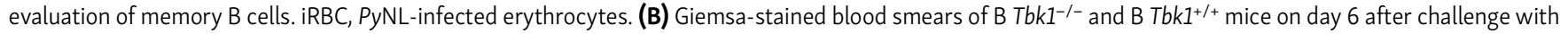

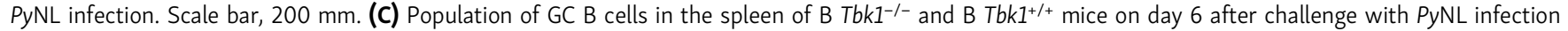

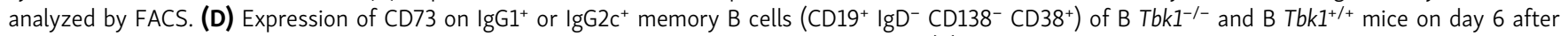
challenge with PyNL infection analyzed by flow cytometry. MFI, mean fluorescence intensity. (E) Population of $\lg G 1^{+}$and $\lg G 2 \mathrm{c}^{+} \mathrm{GC} \mathrm{B}$ cells in the spleens of B

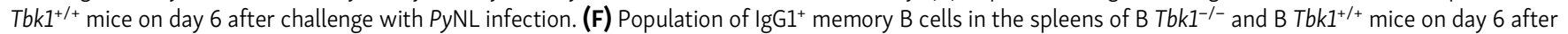

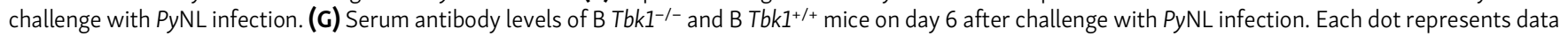
from an individual mouse. $n=5-6$ mice/group. Data are representative of two independent experiments $(A-G)$. Data are shown as mean $\pm S D$. ${ }^{*}, P<0.05$; **, $\mathrm{P}<0.01$; Mann-Whitney $t$ test $(\mathrm{A}-\mathrm{G})$.

multiple roles in each cell type, depending on the stimulant and differentiation stage. TBK1 is a downstream molecule of cyclic GMP-AMP synthase (cGAS)-STING activation that leads to the induction of IFN-I. Enhanced GC formation in IFNAR KO mice infected with PyNL suggests that IFNAR is not essential for GC formation, but rather has a negative regulatory role (Sebina et al., 2016). Furthermore, cGAS in B cells was shown not to be responsible for GC formation; instead, its expression in innate immune cells mediates B cell responses (Hahn et al., 2018). TBK1 is also involved in autophagy by phosphorylating autophagy receptors to facilitate the recruitment of LC3 molecules (Richter et al., 2016). A study using B cell-specific Atg7-deficient mice suggested that autophagy is not essential for GC formation and maintenance, although it is crucial for memory B cell maintenance (Chen et al., 2014). Collectively, these studies suggest that the mechanism of TBK1 regulation of GC differentiation is beyond its role in nucleic acid recognition, IFN-I signaling, and autophagy.

It was previously shown that TBK1 regulates IgA class switching, while it did not affect IgG class switching or antibody production (Jin et al., 2012). Therefore, our study clearly suggests the possibility that the increased IgA production in B cellintrinsic TBK1-deficient mice shown by Jin et al. originated from GC-independent responses. However, whether IgA ${ }^{+}$GC in Peyer's patches is regulated by TBK1 in a manner similar to that in spleen and LNs requires further investigation. Consistently, we found that TBK1 deficiency did not abolish serum IgG production upon immunization or infection; however, these antibodies 
arose from GC-independent plasmablasts. Without affinity maturation in the GC, the quality of antibodies produced was compromised and could not protect the mice from malaria infection. It was long believed that IgG class switching occurs in the $G C$, but a recent study found that IgG class switching actually happens before B cells enter the GC (Roco et al., 2019), which explains the detection of serum IgG in the absence of GC. Despite the robust IgG2c antibody induction upon PyNL infection, the lack of GC-derived IgG1 in B cell-intrinsic TBK1-deficient mice suggests the importance of IgG1 for sterile protection against malaria and that antibody quality is more crucial than the magnitude of antibody production. Our finding that $\mathrm{IgGl}^{+} \mathrm{B}$ cells instead of IgG2 $\mathrm{c}^{+} \mathrm{B}$ cells were selected to enter GC during PyNL infection implies the difference in their antigen affinity, because generally higher-affinity B cells outcompete lower-affinity B cells for GC seeding (Schwickert et al., 2011).

A recent study developed a small molecule inhibitor of TBK1 and IKKع, WEHI-112, to treat antibody-dependent arthritis (Louis et al., 2019). It was suggested that the drug might target the innate immune cells to suppress IFN-I and IL-6 and may directly or indirectly suppress Tfh cells, which led to GC inhibition. With our current findings, it is plausible that the TBK1 inhibitor targets B cells directly to suppress GC formation. Surprisingly, we found that $\mathrm{CD}^{+} \mathrm{T}$ cell-intrinsic TBK1 had a redundant role in GC differentiation, which is in contrast to a report showing that adoptive transfer of lymphocytic choriomeningitis virus (LCMV)-specific CD4 ${ }^{+} \mathrm{T}$ cells knocked down for TBK1 failed to induce GC formation upon acute LCMV infection due to impaired Tfh cell maturation (Pedros et al., 2016). The discrepancy could possibly be due to the homing ability of the adoptively transferred TBK1-deficient $\mathrm{CD} 4^{+} \mathrm{T}$ cells to the $\mathrm{T}$ cell zone, as Tbk1-deficient $\mathrm{T}$ cells were shown to exhibit impaired migration ( $\mathrm{Yu}$ et al., 2015). Adoptive transfer of $\mathrm{CD} 4^{+}$ $\mathrm{T}$ cells into a $\mathrm{Cd} 4^{\mathrm{cre}} \mathrm{Bcl} 6^{\mathrm{f} / \mathrm{f}}$ host constitute only a small proportion of $\mathrm{T}$ cells among the pool of endogenous host $\mathrm{T}$ cells, which may limit the interaction with cognate B cells due to competition with endogenous Bcl6-deficient T cells. Complete deletion of Tbk1 in $\mathrm{CD} 4^{+} \mathrm{T}$ cells using $\mathrm{Cd} 4^{\text {cre }} \mathrm{Tbk} \mathrm{I}^{\text {flox }}$ mice allowed us to overcome these limitations in this study.

Initial antigen encounter through the BCR is essential for both GC-dependent and GC-independent humoral responses. Although high-affinity B cells outcompete low-affinity B cells for GC seeding, even B cells with low BCR affinity are able to migrate to the $T-B$ border to receive $T$ cell help to form the $G C$ in the absence of high-affinity B cells (Dal Porto et al., 2002; Schwickert et al., 2011), indicating that $\mathrm{T}$ cell help plays a crucial role in determining GC commitment. However, recent evidence also suggested that overactivation of $\mathrm{BCR}$ signaling induces plasmablast and GC B cell death (Yam-Puc et al., 2021). The ability of Tbk1-deficient B cells to induce normal Tfh cell differentiation suggests that antigen presentation was not impaired. The amount of $\mathrm{T}$ cell help through $\mathrm{CD} 40$ signaling is particularly important for B cell fate decision. GC formation is abolished in CD40-deficient mice (Kawabe et al., 1994); however, CD40-mediated gene signatures were only found in Pre-GC and post-GC memory B cells and were absent during GC expansion (Basso et al., 2004). We found that TBK1 is not required in the initiation of Pre-GC differentiation, but rather involved in the fate decision of Pre-GC, by limiting CD40 and BCR signaling for the progression of GC differentiation. Excessive CD40 signaling was shown to halt Pre-GC further differentiation into GC through sustained noncanonical NF- $\mathrm{kB}$-activated IRF4 expression (Zhang et al., 2017). Although CD40-induced noncanonical NF- $\kappa B$ and IRF4 are essential for GC initiation, the expression of RelB and IRF4 is transient during GC initiation and absent from mature GC (De Silva et al., 2016; Willis et al., 2014). Increased noncanonical NF- $\kappa$ B and IRF4 expression in TBK1-deficient PreGC inhibits GC differentiation by inhibiting BCL6 expression, as high IRF4 expression directly binds to the promoter site of the Bcl6 gene as a transcription repressor (Saito et al., 2007). CD40induced IRF4 was also shown to down-regulate ICOSL expression in B cells (Ochiai et al., 2018); therefore, it is likely that the high IRF4 expression in $\mathrm{Tbk1}^{-/-} \mathrm{B}$ cells caused unsustainable ICOSL-ICOS interaction between Tfh cells and cognate B cells. Additionally, we found that TBK1 is involved in the synergy of CD40 and BCR activation to negatively regulate IRF4 expression and BCR-mediated AKT T308 phosphorylation in Pre-GC.

AKT phosphorylation at T308 and S473 was shown to be TBK1 dependent in fibroblasts upon stimulation with glucose or growth factors (Ou et al., 2011); however, the loss of TBK1 unexpectedly promotes pAKT at $\mathrm{S} 473$ in $\mathrm{CD}^{+}{ }^{+} \mathrm{T}$ cells upon TCR activation, suggesting cell type specificity and stimulant dependency (Yu et al., 2015). Therefore, although TBK1 has been shown to phosphorylate AKT at T308 in other non-B cells, there has been no information indicating whether TBK1 also phosphorylates AKT at T308 in B cells. Our data show that TBK1 acts as a negative regulator of AKT phosphorylation at T308 in PreGC B cells. Notably, a recent paper showed that increased pAKT T308 inhibits pAKT S473 to allow migration of GC dark zone $\mathrm{B}$ cells to reenter the GC light zone to interact with T cells (Luo et al., 2019). Therefore, the increased pAKT T308 in Tbk1 ${ }^{-/-}$ B cells before GC maturation might inhibit pAKT S473 in early $B C R$ activation and sustain Pre-GC interaction with $T$ cells and thus inhibit Pre-GC progression into GC. Furthermore, our data also showed increased CD40 signaling in $\mathrm{Tbk1}^{-/-}$Pre-GC, suggesting that the increased pAKT T308 in Tbk1 ${ }^{-/-}$Pre-GC might promote $\mathrm{T}$ cell interaction and thus enhanced $\mathrm{CD} 40$ signaling.

CD40 activation recruits TRAF proteins to its cytosolic domain, leading to downstream signaling (Elgueta et al., 2009). TRAF2 is involved in CD40 signaling for the induction of noncanonical NF- $\mathrm{kB}$. Dephosphorylation of TRAF2 at S11 was shown to be required for NF- $\mathrm{KB}$-inducing kinase (NIK) accumulation to drive noncanonical NF- $\kappa \mathrm{B}$ in CD40-stimulated naive B cells (Workman et al., 2020). Consistently, we found that CD40 stimulation gradually dephosphorylates TRAF2 over a time course in a TBK1-dependent manner. Interestingly, the trend of TRAF2 dephosphorylation coincides with TBK1 dephosphorylation upon CD40 stimulation. Notably, TBK1 is constitutively phosphorylated in unstimulated naive B cells, but not in other non-B cells, in the spleen. Together, these findings further suggest that phospho-TBK1-mediated TRAF2 S11 phosphorylation is required to constantly degrade NIK to prevent spontaneous noncanonical NF- $\kappa B$ activation in the absence of $C D 40$ stimulation. TRAF2-deficient $B$ cells also exhibited a phenotype 
similar to that of TBK1-deficient B cells with impaired GC formation (Gardam et al., 2011), suggesting the importance of TBK1 in CD40 regulation via TRAF2 for optimal GC formation.

The GC provides stringent quality control for B cells through clonal selection, coupled with several rounds of somatic hypermutation to produce antigen-specific high-affinity B cells that exit as either long-lived plasma cells or memory B cells. Upon reencountering antigen, GC-derived memory $B$ cells can immediately differentiate into ASCs or reenter the GC for further rounds of somatic hypermutation to increase its affinity maturation. Memory B cells are heterogeneous, and recently a few markers have been used to identify subsets of antigen-specific memory B cells (Tomayko et al., 2010). CD73 is an ecto- $5^{\prime}$-nucleotidase expressed by a subset of memory B cells that correlates with somatic hypermutation (Anderson et al., 2007; Kaji et al., 2012) and therefore is considered to be a good candidate to distinguish GC-derived memory B cells. $\mathrm{CD} 80^{+}$memory B cells were shown to immediately differentiate into plasmablasts upon antigen reencounter instead of entering the GC (ZuccarinoCatania et al., 2014), while $\mathrm{CD} 80^{+}$memory B cells were also induced in B cell-intrinsic Bcl6-deficient mice that lack the GC (Kaji et al., 2012), suggesting its GC-independent origin. Notably, we noticed that CD80 expression was up-regulated in TBK1deficient Pre-GC, which is consistent with the notion that GCindependent memory B cells arise early before GC formation. Challenge with $P y$ NL infection suggests that these GCindependent memory B cells confer limited protection for sterile immunity.

Plasmodium spp. parasites evolve various strategies to evade host immunity, making it difficult to develop a vaccine that can provide sterile immunity (Rénia and Goh, 2016). In humans, recovery from malaria infection does not induce long-lasting immune memory to protect from subsequent infection, although the partial immunity is able to reduce parasite burden and disease complications (Lee and Coban, 2018). Recent studies showed that the impaired humoral immunity in malaria patients is associated with impaired Tfh cell phenotypes (Obeng-Adjei et al., 2015) that give rise to short-lived atypical memory B cells (Weiss et al., 2009; Obeng-Adjei et al., 2017) that produce transient antibodies. However, there is a lack of evidence whether malaria has a direct pressure on B cells to suppress GC differentiation to give rise to long-lived plasma cells and memory B cells. The gene expression of Tbk1 in human PBMCs was found to correlate with the severity of acute Plasmodium falciparum infection (Yamagishi et al., 2014). However, Plasmodium parasites were shown to evade host immunity by antagonizing TBK1 activity. Indeed, host receptor transporter protein 4 and FOS-like antigen 1 induced by malaria infection were shown to inhibit TBK1 phosphorylation and TBK1 interaction with IFN-I signaling molecules, exacerbating the severity of infection (He et al., 2020; Cai et al., 2017). In addition, several studies have shown the inhibitory effects of parasite factors or host factors on B cell immunity during malaria, such as Plasmodium-expressing repetitive interspersed families of polypeptides (Saito et al., 2017), ApiAP2 (Akkaya et al., 2020a), and plasmepsin-4 (Spaccapelo et al., 2010), as well as host LAIR1 and LILRB1, which are expressed on host immune cells, including B cells
(Saito et al., 2017), or indirectly through the dysregulation of CD4 ${ }^{+} \mathrm{T}$ cells (Butler et al., 2011; Zander et al., 2015; Kurup et al., 2017; Obeng-Adjei et al., 2017). Together, this evidence suggests that malaria evades B cell immunity through multiple mechanisms, including the inhibition of TBK1 activity in B cells to limit GC formation, thereby suppressing long-lasting immune memory. Here, for the first time, we address the crucial role of TBK1 in GC formation and highlight its importance in long-lasting humoral responses required for sterile immunity against malaria infection.

In conclusion, our study demonstrated the role of B cellintrinsic TBK1 in the B cell fate decision for GC differentiation and the importance of GC-dependent antibody production and long-lived memory B cell formation for the protection against pathogen reinfection. The involvement of TBK1 in various signaling pathways makes it act as a double-edged sword in different diseases. TBK1 is required for IFN-I-mediated antiviral immunity, while here we additionally showed its importance in GC-mediated humoral immunity. However, TBKl is also involved in the pathogenesis of autoimmune diseases (Louis et al., 2018). TBK1 inhibitors such as amlexanox have been used in clinical treatment for asthma (Inagaki et al., 1992) and have recently been proposed for the treatment of obesity-related metabolic disease (Reilly et al., 2013; Oral et al., 2017). Our findings suggest that TBK1 inhibitors should be administered with caution, considering their possible effect on humoral immunity in case of infection and vaccination. Moreover, the timing of TBK1 inhibitor administration may be important to target TBK1 in specific cell types during disease progression and to prevent its suppressive effects on vaccine efficacy.

\section{Materials and methods \\ Mice}

WT C57BL/6J mice were purchased from CLEA Japan. Female CD $45.1^{+}$C57BL/6J mice were purchased from Sankyo Laboratory Service. $\mu M T$ mice were purchased from The Jackson Laboratory. Cd4-cre mice (The Jackson Laboratory) were crossed with $B c l 6^{\text {flox/flox }}$ to generate $C d 4^{\text {cre }} \mathrm{Bcl} 6^{\mathrm{f} / \mathrm{f}}$ mice and $\mathrm{Cd} 4^{\mathrm{wt}} \mathrm{Bcl}{ }^{\mathrm{f} / \mathrm{f}}$ mice (Lee et al., 2019; Ise et al., 2014). Mbl-cre mice, kindly provided by M. Reth (University of Freiburg, Freiburg, Germany; Hobeika et al., 2006), and Cd4-cre mice were crossed with Tbk1 $1^{\text {flox/flox }}$ mice (Taconic) to generate $M b^{1}{ }^{\text {re/wt }} T b k 1^{\mathrm{f} / \mathrm{f}}$ and $C d 4^{\text {cre/wt }} \mathrm{Tbk1^{ \textrm {f } / \mathrm { f } }}$ mice, respectively. Tbk1 $\mathrm{I}^{\mathrm{f} / \mathrm{f}}$ littermates were used as control WT counterparts. Animal experiments were conducted in accordance with institutional guidelines and approved by the review board for animal experiments of The Institute of Medical Science, The University of Tokyo (approval PA19-48).

\section{Malaria infection and treatment}

Mice were infected with $10^{5} \mathrm{PyNL}$-infected erythrocytes i.p. or otherwise as mentioned in the figure legends (Lee et al., 2017). Parasitemia during the course of infection was quantified by Giemsa-stained blood smears or flow cytometry (Lelliott et al., 2014). In Fig. 7, PyNL-infected mice were treated with $10 \mathrm{mg} / \mathrm{kg}$ HCQ orally from day 15 to day 30 after infection. Parasitemia resolution was confirmed by Giemsa-stained blood smears. 
HCQ-treated mice recovered from $P y$ NL infection were reinfected with $5 \times 10^{5} \mathrm{PyNL}$-infected erythrocytes $1 \mathrm{wk}$ after the end of HCQ treatment to prevent the prophylactic effect of HCQ.

\section{Immunization}

Mice were immunized with $100 \mu \mathrm{g}$ NIP-OVA (Biosearch Technologies) mixed with alum (InvivoGen) intradermally (i.d.). Sera were collected for antibody assay, inguinal LNs were collected for cellular analysis by flow cytometry, and spleens were collected for immunohistochemical analysis on day 12 or day 21 after immunization.

\section{Mixed bone marrow chimera}

Bone marrow mixtures from female Ly5.1- $M b 1^{\text {cre/wt }} \mathrm{Tbk}^{\mathrm{f} / \mathrm{f}}$ mice, Ly5.1 $1^{+}$WT mice, and $\mu M T$ mice were mixed at a 1:1:8 ratio and injected i.v. into lethally irradiated $(8.5 \mathrm{~Gy})$ male $\mu \mathrm{MT}$ mice. Mice were fed enrofloxacin (Elanco) in drinking water for $5 \mathrm{wk}$. Mice were immunized with NIP-OVA and alum i.d. 7 wk after bone marrow transfer. Spleens were analyzed by flow cytometry on day 12 after immunization.

\section{B cell isolation}

Human PBMC purified B cells were isolated by Ficoll-Paque, followed by anti-CD19 magnetic beads (Miltenyi Biotec). Splenic naive $B$ cells were purified using a $B$ cell isolation kit by negative selection (Miltenyi Biotec). Splenic Pre-GC and GC B cells were first enriched by streptavidin magnetic beads conjugated with a mixture of biotinylated anti-CD11b, anti-CD11c, anti-IgD, antiCD138, anti-CD3, and anti-Ter119 (Miltenyi Biotec), followed by cell sorting using a BD FACSAria III Cell Sorter. Splenic Pre-GC

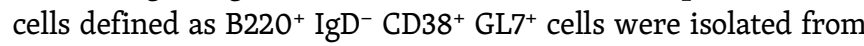
PyNL-infected mice on day 9 after infection. Splenic mature GC B cells defined as B220 IgD $^{-}$CD38 $8^{-} \mathrm{GL7}^{+}$cells were purified from mice recovered from $P y$ NL infection after day 28 infection.

\section{RNA-seq}

$5 \times 10^{4}$ cells were directly sorted into TRIzol reagent (Invitrogen). RNAs were purified following the manufacturer's instructions with the addition of RNA grade glycogen (Thermo Fisher Scientific). RNA integrity number $>9.7$ was confirmed using the RNA 6000 Nano kit on an Agilent 2100 Bioanalyzer. DNA libraries were constructed using the TruSeq Stranded mRNA Sample Prep Kit. RNA-seq was performed by the Genome Information Research Center of Osaka University using NovaSeq 6000 (Illumina) in a 100-bp single-end read mode. Sequence reads were mapped to mouse reference genome sequence mm10 using TopHat version 2.0.13, Bowtie2 version 2.2.3, and SMtools version 0.1.19. Fragments per kilobase of exon per million reads mapped were calculated by Cufflinks version 2.2.1. Data were analyzed using iDEP.91 and GSEA software version 4.0.3 (Subramanian et al., 2005). GSEA results were analyzed based on the collection of MSigDB gene sets and gene signatures upregulated or down-regulated by CD40 and BCR stimulation as described previously (Victora et al., 2010). GO enrichment analysis was performed using iDEP.91. Heatmaps for differentially expressed genes (DEGs) were generated by iDEP.91 or Morpheus after filtering out genes with low statistical significance
$(P>0.05)$. Genes presented in the heatmaps were arranged from top to bottom with descending differential expression. The RNA-seq data are available in the Gene Expression Omnibus database (accession no. GSE188659).

\section{Antibody assay}

Antibody titers were measured from sera collected from PyNLinfected or immunized mice by ELISA. High-binding 96-well microtiter plates were coated overnight with $10 \mu \mathrm{g} / \mathrm{ml}$ PyNL parasite crude extract, uninfected RBC extract, or 4-Hydroxy-3nitrophenylacetyl hapten conjugated BSA ratio 30 (Biosearch Technologies) and blocked with $5 \%$ skim milk or $1 \%$ BSA (Nacalai Tesque). Sera were serially diluted, and antibodies were detected using HRP-conjugated goat anti-mouse IgG1, IgG2c, IgG3, and IgM antibodies (SouthernBiotech). Anti-P $y$ NL antibody levels were calculated by subtracting autoantibodies against uninfected RBCs. Antibody avidity assays were performed as described (Coban et al., 2004). Briefly, after overnight incubation of sera in antigen-coated plates, antibodies were dissociated with various concentrations of sodium thiocyanate at $0,1,2$, or $4 \mathrm{M}$ for $15 \mathrm{~min}$. Plates were washed extensively six times before proceeding to subsequent antibody detection by ELISA as described above.

\section{In vitro and ex vivo $B$ cell stimulation}

B cells were cultured in RPMI 1640 (Nacalai) supplemented with 10\% FBS (Sigma-Aldrich), penicillin and streptomycin antibiotics (Nacalai), Hepes (Nacalai), glutamine (Nacalai), sodium pyruvate (Nacalai), nonessential amino acids (Nacalai), and $\beta$-mercaptoethanol (Nacalai). Purified naive B cells were stimulated with $1 \mu \mathrm{g} / \mathrm{ml}$ anti-CD40 (HM40-3; eBioscience) or $1 \mu \mathrm{g} / \mathrm{ml}$ $\mathrm{F}\left(\mathrm{ab}^{\prime}\right)_{2}$ goat anti-IgM (16-5092-85; eBioscience) or $1 \mu \mathrm{g} / \mathrm{ml} \mathrm{F}\left(\mathrm{ab}^{\prime}\right)_{2}$ goat anti-IgG (16-5098-85; eBioscience). For ex vivo stimulation of Pre-GC, splenocytes from day $9 \mathrm{P} y \mathrm{NL}$-infected mice were stimulated with $1 \mu \mathrm{g} / \mathrm{ml}$ anti-CD40 (eBioscience) and/or with $1 \mu \mathrm{g} / \mathrm{ml}$ anti-IgG (eBioscience) and $1 \mu \mathrm{g} / \mathrm{ml}$ anti-IgM (eBioscience). Cells were harvested at the time points indicated in the figure legends.

\section{Cell proliferation and apoptosis assay}

$5 \times 10^{4}$ cells were stained with prewarmed CellTrace Violet (CTV; Invitrogen) in serum-free RPMI for $10 \mathrm{~min}$ at $37^{\circ} \mathrm{C}$ and washed twice with RPMI containing $10 \%$ FCS. Cells were stimulated with $1 \mu \mathrm{g} / \mathrm{ml}$ anti-CD40 (eBioscience) and/or with $1 \mu \mathrm{g} / \mathrm{ml}$ anti-IgM (eBioscience). After $4 \mathrm{~d}$, cells were washed with cold PBS and proceeded to flow cytometric analysis. Cell proliferation was indicated by the dilution of CTV fluorescence intensity. For the in vivo EdU pulse assay, mice were injected with $1 \mu \mathrm{g}$ EdU in PBS, and spleens were collected $30 \mathrm{~min}$ later. Cell cycle and proliferation were detected using the Click-iT EdU assay kit (Invitrogen) and SYTOX AADvanced (Invitrogen). For cell death and apoptosis assay, cells were stained with the CellEvent Caspase-3/7 Green Flow Cytometry Assay Kit (Invitrogen).

\section{Flow cytometry}

Spleen or inguinal LNs were crushed on ice and were passed through 70- $\mu \mathrm{m}$ mesh to collect single-cell suspensions. Erythrocytes were lysed using ammonium-chloride-potassium lysis 
buffer (Lonza) and washed twice with PBS supplemented with $2 \%$ heat-inactivated FCS. Cells were incubated with Fc blocker (BioLegend) for 5 min at room temperature before staining with fluorophore-conjugated antibody mixtures at $4^{\circ} \mathrm{C}$ for $30 \mathrm{~min}$ for surface antigen staining. Dead cells were excluded using LIVE/ DEAD Fixable Dead Cell Stain (Invitrogen). Cells were fixed and permeabilized with the Foxp3/Transcription Factor Fixation/ Permeabilization kit (eBioscience) for intracellular staining. Detection of phosphoproteins and signaling molecules was performed as described previously (Rip et al., 2020). Briefly, cells were fixed with $2 \%$ paraformaldehyde (Nacalai Tesque) for 10 min, permeabilized with permeabilization buffer (eBioscience), and stained with Fc blocker followed by rabbit antimouse primary antibodies (Cell Signaling Technology) against pAKT T308 (D25E6), pAKT S473 (193H12), c-Myc (D84C12), p65 (D14E12), and p52 or RelB (C1E4) for $30 \mathrm{~min}$ at $4^{\circ} \mathrm{C}$. After washing with permeabilization buffer, samples were further stained with Alexa Fluor 488-conjugated goat anti-rabbit secondary antibody (Invitrogen) together with the mixture of fluorophore-conjugated antibodies for surface antigen staining. Fluorescence minus one control contains all antibodies except primary antibodies. Samples were analyzed using an LSRFortessa flow cytometer (BD Biosciences). Data were analyzed with FlowJo 10.7.1. Anti-B220 (RA3-6B2), IgD (11-26c.2a), IgG1 (A851), IgM (RMM-1), CD138 (281-2), CD38 (90), TCR $\beta$ (H57-597), CD4 (RM-4-5), CD44 (IM7), CXCR5 (L138D7), BCL6 (7D1), CTLA4 (UC10-4B9), ICOS (C398.4A) and IRF4 (IRF4.3E4) were purchased from BioLegend. Anti-GL7 (GL-7), PD-1 (J43), Foxp3 (FJK-16s) and IL-21 (FFA21) were purchased from eBioscience. Goat anti-mouse IgG2c human ads-PE were purchased from SouthernBiotech.

\section{Western blotting}

Purified B cell populations were lysed with radioimmunoprecipitation assay buffer (Nacalai Tesque) supplemented with protease inhibitor cocktail (Sigma-Aldrich), phosphatase inhibitor cocktail III (Sigma-Aldrich), and PMSF (Cell Signaling Technology). Subcellular fractionation was performed using the Cell Fractionation Kit (Cell Signaling Technology). Protein concentrations were quantified using the Pierce BCA Protein Assay Kit (Thermo Fisher Scientific). Cell lysates were boiled at $95^{\circ} \mathrm{C}$ for 5 min with NuPAGE LDS Sample Buffer (Invitrogen) and NuPAGE Sample Reducing Agent (Invitrogen). Proteins were separated by SDS-PAGE electrophoresis in NuPAGE 4-12\% BisTris Mini Gel (Invitrogen) at 100 V. Proteins were transferred to polyvinylidene fluoride membrane using the iBlot2 gel transfer device (Thermo Fisher Scientific). Membranes were blocked with $5 \%$ skim milk or BSA in Tris-buffered saline with Tween 20 (Nacalai Tesque) before overnight incubation with the following rabbit anti-mouse primary antibodies (Cell Signaling Technology): phospho-TBK1 (D52C2), TBK1 (D1B4), phospho-TRAF2 Ser11 (E2B6L), TRAF2 (C192), NIK, phospho-NF-kB p65 Ser536, NF-kB2 p100/p52, RelB (C1E4), $\beta$-actin (D6A8), $\beta$-tubulin (D2N5G), or lamin B1 (D4Q4Z). Goat anti-rabbit IgG HRP (Cell Signaling Technology) was used as a secondary antibody. Luminescence was captured and measured using an Amersham Imager 600 (GE Healthcare). The protein amount was normalized with the band intensity of the loading control. WB stripping solution (Nacalai Tesque) was used to remove membranebound antibodies before subsequent antibody staining.

\section{Immunohistochemical analysis}

Spleens were collected directly into $4 \%$ paraformaldehyde on ice and fixed at $4^{\circ} \mathrm{C}$ overnight. Samples were transferred into $30 \%$ sucrose solution at $4^{\circ} \mathrm{C}$ overnight with constant shaking. Samples were then embedded in Tissue-Tek O.C.T. Compound (Sakura Finetek) and instant frozen at $-80^{\circ} \mathrm{C}$. Samples were then sectioned with a cryostat at $10-\mu \mathrm{m}$ thickness and $-20^{\circ} \mathrm{C}$. Sections were washed with PBS and blocked for 30 min with $3 \%$ BSA in Tris-buffered saline with Tween 20 . Sections were stained with rat anti-mouse Alexa Fluor 488-GL7 (GL7; BioLegend) overnight at $4^{\circ} \mathrm{C}$, washed, and further incubated overnight at $4^{\circ} \mathrm{C}$ with biotin-CD4 (RM4-5; BioLegend), followed by staining with streptavidin Alexa Fluor 405 (Invitrogen) for $2 \mathrm{~h}$ at room temperature and finally with Alexa Fluor 647-IgD (11-26c.2a; BioLegend) for $1 \mathrm{~h}$ at room temperature. Stained tissue sections were mounted on coverslips using fluorescence mounting medium (Dako). Tissue sections were observed and captured with an all-in-one fluorescence microscope (Keyence).

\section{Statistical analyses}

Reported $n$ values are the total number of samples per group. Each sample represents an individual mouse. Graphs were plotted and analyzed with GraphPad Prism 9.0 software. The Mann-Whitney $t$ test was used for comparing two groups, while one-way ANOVA was used for comparing more than two groups. Survival between two groups was compared by log-rank Mantel-Cox test.

\section{Online supplemental material}

Fig. S1 shows Tfh and GC B cell formation during the course of PyNL infection and parasitemia and survival of Th celldeficient mice. Fig. S2 shows phospho-TBK1 in purified human $B$ cells and mouse splenic B cells; depletion efficiency of B Tbk1 ${ }^{-/-}$ mice; and B cell subsets in spleen, peritoneum, and bone marrow. Fig. S3 shows a comparison of antibody responses and ASC formation between $\mathrm{B} \mathrm{Tbk1^{-/- }}$ mice and $\mathrm{B} \mathrm{Tbk1^{+/+ }}$ mice following PyNL infection or NIP-OVA + alum immunization. Fig. S4 shows heatmaps of RNA-seq data for the GO biological process pathway related to regulation of signal transduction and TBK1-dependent genes up-regulated by CD40 or BCR stimulation in Pre-GC. Fig. S5 shows a comparison of CD40-induced NF- $\mathrm{KB}$ activation between $\mathrm{Tbk1}^{-/-}$and $\mathrm{Tbk1}^{+/+}$naive B cells. Table S1 shows RNA-seq data of $\mathrm{Tbk1}^{-/-}$and $\mathrm{Tbk1}^{+/+}$Pre-GCs isolated from PyNLinfected mice.

\section{Acknowledgments}

We thank D. Okuzaki from Osaka University for performing RNA-seq.

The authors acknowledge funding from the Japan Science and Technology Agency CREST program (C. Coban and K.J. Ishii); the Japan Agency for Medical Research and Development (17fm0208021h0001 [C. Coban]); the International Joint 
Research Project (C. Coban and A.K. Simon); a Mitsubishi UFJ vaccine development grant (C. Coban and M.S.J. Lee) of the Institute of Medical Science, University of Tokyo; and in part by Japan Society for the Promotion of Science KAKENHI grants JP19K16833 (B. Temizoz) and JP 20K16234 (M.S.J. Lee).

Author contributions: M.S.J. Lee and C. Coban designed the experiments, interpreted data, and wrote the manuscript. M.S.J. Lee conducted the experiments. T. Inoue, W. Ise, K.J. Ishii, J.-I. Inoue, and T. Kurosaki contributed reagents and advised on experimental design and data interpretation. J.B. Wing contributed to flow cytometry analysis of Tfh and GC. A. Patil and J. Matsuo-Dapaah analyzed the RNA-seq data. J. Matsuo-Dapaah helped in animal breeding and infection. S. Akira, S. Sakaguchi, B. Temizoz, K. Kobiyama, T. Hayashi, J.S. Bezbradica, A.K. Simon, S. Nagatoishi, and $\mathrm{K}$. Tsumoto provided critical reagents and advice. C. Coban and K.J. Ishii supervised the project. All authors read and approved the final version of the manuscript.

Disclosures: A. Patil reported personal fees from Combinatics Inc. outside the submitted work. No other disclosures were reported.

Submitted: 24 June 2021

Revised: 20 October 2021

Accepted: 17 November 2021

\section{References}

Akkaya, M., A. Bansal, P.W. Sheehan, M. Pena, A. Molina-Cruz, L.M. Orchard, C.K. Cimperman, C.F. Qi, P. Ross, T. Yazew, et al. 2020a. A singlenucleotide polymorphism in a Plasmodium berghei ApiAP2 transcription factor alters the development of host immunity. Sci. Adv. 6: eaaw6957. https://doi.org/10.1126/sciadv.aaw6957

Akkaya, M., K. Kwak, and S.K. Pierce. 2020b. B cell memory: building two walls of protection against pathogens. Nat. Rev. Immunol. 20:229-238. https://doi.org/10.1038/s41577-019-0244-2

Anderson, S.M., M.M. Tomayko, A. Ahuja, A.M. Haberman, and M.J. Shlomchik. 2007. New markers for murine memory B cells that define mutated and unmutated subsets. J. Exp. Med. 204:2103-2114. https://doi .org/10.1084/jem.20062571

Arroyo, E.N., and M. Pepper. 2020. B cells are sufficient to prime the dominant $\mathrm{CD}^{+}{ }^{+} \mathrm{Tfh}$ response to Plasmodium infection. J. Exp. Med. 217: e20190849. https://doi.org/10.1084/jem.20190849

Basso, K., U. Klein, H. Niu, G.A. Stolovitzky, Y. Tu, A. Califano, G. Cattoretti, and R. Dalla-Favera. 2004. Tracking CD40 signaling during germinal center development. Blood. 104:4088-4096. https://doi.org/10.1182/ blood-2003-12-4291

Butler, N.S., J. Moebius, L.L. Pewe, B. Traore, O.K. Doumbo, L.T. Tygrett, T.J. Waldschmidt, P.D. Crompton, and J.T. Harty. 2011. Therapeutic blockade of PD-L1 and LAG-3 rapidly clears established blood-stage Plasmodium infection. Nat. Immunol. 13:188-195. https://doi.org/10.1038/ni .2180

Cai, B., J. Wu, X. Yu, X. Su, and R.-F. Wang. 2017. FOSL1 inhibits type I interferon responses to malaria and viral infections by blocking TBK1 and TRAF3/TRIF interactions. MBio. 8:1-14. https://doi.org/10.1128/mBio $.02161-16$

Calado, D.P., Y. Sasaki, S.A. Godinho, A. Pellerin, K. Köchert, B.P. Sleckman, I.M. de Alborán, M. Janz, S. Rodig, and K. Rajewsky. 2012. The cell-cycle regulator c-Myc is essential for the formation and maintenance of germinal centers. Nat. Immunol. 13:1092-1100. https://doi.org/10.1038/ ni. 2418

Chen, M., M.J. Hong, H. Sun, L. Wang, X. Shi, B.E. Gilbert, D.B. Corry, F. Kheradmand, and J. Wang. 2014. Essential role for autophagy in the maintenance of immunological memory against influenza infection. Nat. Med. 20:503-510. https://doi.org/10.1038/nm.3521
Coban, C., M.T. Philipp, J.E. Purcell, D.B. Keistr, M. Okulate, D.S. Martin, and N. Kumar. 2004. Induction of Plasmodium falciparum transmissionblocking antibodies in nonhuman primates by a combination of DNA and protein immunizations. Infect. Immun. 72:253-259. https://doi.org/ 10.1128/IAI.72.1.253-259.2004

Coban, C., M.S.J. Lee, and K.J. Ishii. 2018. Tissue-specific immunopathology during malaria infection. Nat. Rev. Immunol. 18:266-278. https://doi .org $/ 10.1038 /$ nri.2017.138

Cyster, J.G., and C.D.C. Allen. 2019. B cell responses: cell interaction dynamics and decisions. Cell. 177:524-540. https://doi.org/10.1016/j.cell.2019.03 .016

Dal Porto, J.M., A.M. Haberman, G. Kelsoe, and M.J. Shlomchik. 2002. Very low affinity B cells form germinal centers, become memory B cells, and participate in secondary immune responses when higher affinity competition is reduced. J. Exp. Med. 195:1215-1221. https://doi.org/10 $.1084 /$ jem.20011550

De Silva, N.S., M.M. Anderson, A. Carette, K. Silva, N. Heise, G. Bhagat, and U. Klein. 2016. Transcription factors of the alternative NF- $\kappa B$ pathway are required for germinal center B-cell development. Proc. Natl. Acad. Sci. USA. 113:9063-9068. https://doi.org/10.1073/pnas .1602728113

Dominguez-Sola, D., G.D. Victora, C.Y. Ying, R.T. Phan, M. Saito, M.C. Nussenzweig, and R. Dalla-Favera. 2012. The proto-oncogene MYC is required for selection in the germinal center and cyclic reentry. Nat. Immunol. 13:1083-1091. https://doi.org/10.1038/ni.2428

Elgueta, R., M.J. Benson, V.C. De Vries, A. Wasiuk, Y. Guo, and R.J. Noelle. 2009. Molecular mechanism and function of CD40/CD40L engagement in the immune system. Immunol. Rev. 229:152-172. https://doi.org/10 $.1111 / j .1600-065 X .2009 .00782 . x$

Elsner, R.A., and M.J. Shlomchik. 2020. Germinal center and extrafollicular B cell responses in vaccination, immunity, and autoimmunity. Immunity. 53:1136-1150. https://doi.org/10.1016/j.immuni.2020.11.006

Gardam, S., V.M. Turner, H. Anderton, S. Limaye, A. Basten, F. Koentgen, D.L. Vaux, J. Silke, and R. Brink. 2011. Deletion of cIAP1 and cIAP2 in murine B lymphocytes constitutively activates cell survival pathways and inactivates the germinal center response. Blood. 117:4041-4051. https://doi .org/10.1182/blood-2010-10-312793

Hahn, W.O., N.S. Butler, S.E. Lindner, H.M. Akilesh, D.N. Sather, S.H. Kappe, J.A. Hamerman, M. Gale, W.C. Liles, and M. Pepper. 2018. cGASmediated control of blood-stage malaria promotes Plasmodium-specific germinal center responses. JCI Insight. 3:e94142. https://doi.org/10.1172/ jci.insight.94142

He, X., A.W. Ashbrook, Y. Du, J. Wu, H.H. Hoffmann, C. Zhang, L. Xia, Y.C. Peng, K.C. Tumas, B.K. Singh, et al. 2020. RTP4 inhibits IFN-I response and enhances experimental cerebral malaria and neuropathology. Proc. Natl. Acad. Sci. USA. 117:19465-19474. https://doi.org/10.1073/pnas 2006492117

Heise, N., N.S. de Silva, K. Silva, A. Carette, G. Simonetti, M. Pasparakis, and U. Klein. 2014. Germinal center B cell maintenance and differentiation are controlled by distinct NF-kB transcription factor subunits. J. Exp. Med. 211:2103-2118. https://doi.org/10.1084/jem.20132613

Helgason, E., Q.T. Phung, and E.C. Dueber. 2013. Recent insights into the complexity of Tank-binding kinase 1 signaling networks: the emerging role of cellular localization in the activation and substrate specificity of TBK1. FEBS Lett. 587:1230-1237. https://doi.org/10.1016/j.febslet.2013.01 .059

Hemmi, H., O. Takeuchi, S. Sato, M. Yamamoto, T. Kaisho, H. Sanjo, T. Kawai, K. Hoshino, K. Takeda, and S. Akira. 2004. The roles of two IkB kinaserelated kinases in lipopolysaccharide and double stranded RNA signaling and viral infection. J. Exp. Med. 199:1641-1650. https://doi.org/10 .1084/jem.20040520

Hobeika, E., S. Thiemann, B. Storch, H. Jumaa, P.J. Nielsen, R. Pelanda, and M Reth. 2006. Testing gene function early in the B cell lineage in mbl-cre mice. Proc. Natl. Acad. Sci. USA. 103:13789-13794. https://doi.org/10 $.1073 /$ pnas.0605944103

Inagaki, M., H. Michimata, K. Minato, Y. Sunaga, S. Kobayashi, G. Tani, and T. Nakazawa. 1992. Inhibitory effect of amlexanox on asthmatic attacks in an aspirin sensitive asthmatic [in Japanese]. Nihon Kyobu Shikkan Gakkai Zasshi. 30:1180-1185.

Ise, W., T. Inoue, J.B. McLachlan, K. Kometani, M. Kubo, T. Okada, and T. Kurosaki. 2014. Memory B cells contribute to rapid Bcl6 expression by memory follicular helper T cells. Proc. Natl. Acad. Sci. USA. 111: 11792-11797. https://doi.org/10.1073/pnas.1404671111

Ishii, K.J., T. Kawagoe, S. Koyama, K. Matsui, H. Kumar, T. Kawai, S. Uematsu, O. Takeuchi, F. Takeshita, C. Coban, et al. 2008. TANK-binding 
kinase-1 delineates innate and adaptive immune responses to DNA vaccines. Nature. 451:725-729. https://doi.org/10.1038/nature06537

Jin, J., Y. Xiao, J.-H. Chang, J. Yu, H. Hu, R. Starr, G.C. Brittain, M. Chang, X. Cheng, and S.-C. Sun. 2012. The kinase TBK1 controls IgA class switching by negatively regulating noncanonical NF- $\kappa B$ signaling. Nat. Immunol. 13:1101-1109. https://doi.org/10.1038/ni.2423

Kaji, T., A. Ishige, M. Hikida, J. Taka, A. Hijikata, M. Kubo, T. Nagashima, Y. Takahashi, T. Kurosaki, M. Okada, et al. 2012. Distinct cellular pathways select germline-encoded and somatically mutated antibodies into immunological memory. J. Exp. Med. 209:2079-2097. https://doi.org/10 $.1084 /$ jem. 20120127

Kawabe, T., T. Naka, K. Yoshida, T. Tanaka, H. Fujiwara, S. Suematsu, N. Yoshida, T. Kishimoto, and H. Kikutani. 1994. The immune responses in CD40-deficient mice: Impaired immunoglobulin class switching and germinal center formation. Immunity. 1:167-178. https://doi.org/10 .1016/1074-7613(94)90095-7

Klein, U., S. Casola, G. Cattoretti, Q. Shen, M. Lia, T. Mo, T. Ludwig, K. Rajewsky, and R. Dalla-Favera. 2006. Transcription factor IRF4 controls plasma cell differentiation and class-switch recombination. Nat. Immunol. 7:773-782. https://doi.org/10.1038/nil357

Kurup, S.P., N. Obeng-Adjei, S.M. Anthony, B. Traore, O.K. Doumbo, N.S. Butler, P.D. Crompton, and J.T. Harty. 2017. Regulatory T cells impede acute and long-term immunity to blood-stage malaria through CTLA-4. Nat. Med. 23:1220-1225. https://doi.org/10.1038/nm.4395

Laidlaw, B.J., and J.G. Cyster. 2021. Transcriptional regulation of memory B cell differentiation. Nat. Rev. Immunol. 21:209-220. https://doi.org/10 .1038/s41577-020-00446-2

Lee, M.S.J., and C. Coban. 2018. Unforeseen pathologies caused by malaria. Int. Immunol. 30:121-129. https://doi.org/10.1093/intimm/dxx076

Lee, M.S.J., K. Maruyama, Y. Fujita, A. Konishi, P.M. Lelliott, S. Itagaki, T. Horii, J. Lin, S.M. Khan, E. Kuroda, et al. 2017. Plasmodium products persist in the bone marrow and promote chronic bone loss. Sci. Immunol. 2:eaam8093. https://doi.org/10.1126/sciimmunol.aam8093

Lee, M.S.J., Y. Natsume-Kitatani, B. Temizoz, Y. Fujita, A. Konishi, K. Matsuda, Y. Igari, T. Tsukui, K. Kobiyama, E. Kuroda, et al. 2019. B cellintrinsic MyD88 signaling controls IFN- $\gamma$-mediated early IgG2c class switching in mice in response to a particulate adjuvant. Eur. J. Immunol. 49:1433-1440. https://doi.org/10.1002/eji.201848084

Lelliott, P.M., S. Lampkin, B.J. McMorran, S.J. Foote, and G. Burgio. 2014. A flow cytometric assay to quantify invasion of red blood cells by rodent Plasmodium parasites in vivo. Malar. J. 13:100. https://doi.org/10.1186/ 1475-2875-13-100

Louis, C., C. Burns, and I. Wicks. 2018. TANK-binding kinase 1-dependent responses in health and autoimmunity. Front. Immunol. 9:434. https:// doi.org/10.3389/fimmu.2018.00434

Louis, C., D. Ngo, D.B. D'Silva, J. Hansen, L. Phillipson, H. Jousset, P. Novello, D. Segal, K.E. Lawlor, C.J. Burns, et al. 2019. Therapeutic effects of a TANK-binding kinase 1 inhibitor in germinal center-driven collageninduced arthritis. Arthritis Rheumatol. 71:50-62. https://doi.org/10 $.1002 /$ art. 40670

Luo, W., F. Weisel, and M.J. Shlomchik. 2018. B cell receptor and CD40 signaling are rewired for synergistic induction of the c-Myc transcription factor in germinal center B cells. Immunity. 48:313-326.e5. https://doi .org/10.1016/j.immuni.2018.01.008

Luo, W., W. Hawse, L. Conter, N. Trivedi, F. Weisel, D. Wikenheiser, R.T. Cattley, and M.J. Shlomchik. 2019. The AKT kinase signaling network is rewired by PTEN to control proximal BCR signaling in germinal center B cells. Nat. Immunol. 20:736-746. https://doi.org/10.1038/s41590-019 -0376-3

Marichal, T., K. Ohata, D. Bedoret, C. Mesnil, C. Sabatel, K. Kobiyama, P. Lekeux, C. Coban, S. Akira, K.J. Ishii, et al. 2011. DNA released from dying host cells mediates aluminum adjuvant activity. Nat. Med. 17: 996-1002. https://doi.org/10.1038/nm.2403

Nurieva, R.I., Y. Chung, G.J. Martinez, X.O. Yang, S. Tanaka, T.D. Matskevitch, Y.-H. Wang, and C. Dong. 2009. Bcl6 mediates the development of $\mathrm{T}$ follicular helper cells. Science. 325:1001-1005. https://doi.org/10.1126/ science. 1176676

Nutt, S.L., and D.M. Tarlinton. 2011. Germinal center B and follicular helper T cells: siblings, cousins or just good friends? Nat. Immunol. 12:472-477. https://doi.org/10.1038/ni.2019

Obeng-Adjei, N., S. Portugal, T.M. Tran, T.B. Yazew, J. Skinner, S. Li, A. Jain, P.L. Felgner, O.K. Doumbo, K. Kayentao, et al. 2015. Circulating Th1cell-type Tfh cells that exhibit impaired B cell help are preferentially activated during acute malaria in children. Cell Rep. 13:425-439. https:// doi.org/10.1016/j.celrep.2015.09.004
Obeng-Adjei, N., S. Portugal, P. Holla, S. Li, H. Sohn, A. Ambegaonkar, J. Skinner, G. Bowyer, O.K. Doumbo, B. Traore, et al. 2017. Malariainduced interferon- $\gamma$ drives the expansion of Tbet ${ }^{\mathrm{hi}}$ atypical memory B cells. PLoS Pathog. 13:e1006576. https://doi.org/10.1371/journal.ppat .1006576

Ochiai, K., M. Maienschein-Cline, G. Simonetti, J. Chen, R. Rosenthal, R. Brink, A.S. Chong, U. Klein, A.R. Dinner, H. Singh, et al. 2013. Transcriptional regulation of germinal center B and plasma cell fates by dynamical control of IRF4. Immunity. 38:918-929. https://doi.org/10 $.1016 /$ j.immuni.2013.04.009

Ochiai, K., H. Kondo, Y. Okamura, H. Shima, Y. Kurokochi, K. Kimura, R. Funayama, T. Nagashima, K. Nakayama, K. Yui, et al. 2018. Zinc fingerIRF composite elements bound by Ikaros/IRF4 complexes function as gene repression in plasma cell. Blood Adv. 2:883-894. https://doi.org/10 .1182/bloodadvances.2017010413

Oral, E.A., S.M. Reilly, A.V. Gomez, R. Meral, L. Butz, N. Ajluni, T.L. Chenevert, E. Korytnaya, A.H. Neidert, R. Hench, et al. 2017. Inhibition of IKK $\varepsilon$ and TBK1 improves glucose control in a subset of patients with type 2 diabetes. Cell Metab. 26:157-170.e7. https://doi.org/10.1016/j.cmet 2017.06.006

Ou, Y.H., M. Torres, R. Ram, E. Formstecher, C. Roland, T. Cheng, R. Brekken, R. Wurz, A. Tasker, T. Polverino, et al. 2011. TBK1 directly engages Akt/ PKB survival signaling to support oncogenic transformation. Mol. Cell. 41:458-470. https://doi.org/10.1016/j.molcel.2011.01.019

Pedros, C., Y. Zhang, J.K. Hu, Y.S. Choi, A.J. Canonigo-Balancio, J.R. Yates, A. Altman, S. Crotty, and K.F. Kong. 2016. A TRAF-like motif of the inducible costimulator ICOS controls development of germinal center TFH cells via the kinase TBK1. Nat. Immunol. 17:825-833. https://doi .org/10.1038/ni.3463

Pérez-Mazliah, D., D.H.L. Ng, A.P. Freitas do Rosário, S. McLaughlin, B. Mastelic-Gavillet, J. Sodenkamp, G. Kushinga, and J. Langhorne. 2015. Disruption of IL-21 signaling affects T cell-B cell interactions and abrogates protective humoral immunity to malaria. PLoS Pathog. 11: e1004715. https://doi.org/10.1371/journal.ppat.1004715

Portugal, S., S.K. Pierce, and P.D. Crompton. 2013. Young lives lost as B cells falter: what we are learning about antibody responses in malaria. J. Immunol. 190:3039-3046. https://doi.org/10.4049/jimmunol.1203067

Reilly, S.M., S.H. Chiang, S.J. Decker, L. Chang, M. Uhm, M.J. Larsen, J.R. Rubin, J. Mowers, N.M. White, I. Hochberg, et al. 2013. An inhibitor of the protein kinases TBK1 and IKK- $\varepsilon$ improves obesity-related metabolic dysfunctions in mice. Nat. Med. 19:313-321. https://doi.org/10.1038/nm.3082

Rénia, L., and Y.S. Goh. 2016. Malaria parasites: the great escape. Front. Immunol. 7:463. https://doi.org/10.3389/fimmu.2016.00463

Richter, B., D.A. Sliter, L. Herhaus, A. Stolz, C. Wang, P. Beli, G. Zaffagnini, P. Wild, S. Martens, S.A. Wagner, et al. 2016. Phosphorylation of OPTN by TBK1 enhances its binding to Ub chains and promotes selective autophagy of damaged mitochondria. Proc. Natl. Acad. Sci. USA. 113: 4039-4044. https://doi.org/10.1073/pnas.1523926113

Rip, J., M.J.W. de Bruijn, A. Kaptein, R.W. Hendriks, and O.B.J. Corneth. 2020. Phosphoflow protocol for signaling studies in human and murine B cell subpopulations. J. Immunol. 204:2852-2863. https://doi.org/10.4049/ jimmunol.1901117

Roco, J.A., L. Mesin, S.C. Binder, C. Nefzger, P. Gonzalez-Figueroa, P.F. Canete, J. Ellyard, Q. Shen, P.A. Robert, J. Cappello, et al. 2019. Classswitch recombination occurs infrequently in germinal centers. Immunity. 51:337-350.e7. https://doi.org/10.1016/j.immuni.2019.07.001

Saito, M., J. Gao, K. Basso, Y. Kitagawa, P.M. Smith, G. Bhagat, A. Pernis, L. Pasqualucci, and R. Dalla-Favera. 2007. A signaling pathway mediating downregulation of BCL6 in germinal center B cells is blocked by BCL6 gene alterations in B cell lymphoma. Cancer Cell. 12:280-292. https://doi .org/10.1016/j.ccr.2007.08.011

Saito, F., K. Hirayasu, T. Satoh, C.W. Wang, J. Lusingu, T. Arimori, K. Shida, N.M.Q. Palacpac, S. Itagaki, S. Iwanaga, et al. 2017. Immune evasion of Plasmodium falciparum by RIFIN via inhibitory receptors. Nature. 552: 101-105. https://doi.org/10.1038/nature24994

Schwickert, T.A., G.D. Victora, D.R. Fooksman, A.O. Kamphorst, M.R. Mugnier, A.D. Gitlin, and M.L.D. Nussenzweig. 2011. A dynamic T celllimited checkpoint regulates affinity-dependent B cell entry into the germinal center. J. Exp. Med. 208:1243-1252. https://doi.org/10.1084/ jem. 20102477

Sebina, I., K.R. James, M.S.F. Soon, L.G. Fogg, S.E. Best, F. de Labastida Rivera, M. Montes de Oca, F.H. Amante, B.S. Thomas, L. Beattie, et al. 2016. IFNAR1-signalling obstructs ICOS-mediated humoral immunity during non-lethal blood-stage Plasmodium infection. PLoS Pathog. 12:e1005999. https://doi.org/10.1371/journal.ppat.1005999 
Shinnakasu, R., and T. Kurosaki. 2017. Regulation of memory B and plasma cell differentiation. Curr. Opin. Immunol. 45:126-131. https://doi.org/10 $.1016 /$ j.coi.2017.03.003

Song, S., and P.D. Matthias. 2018. The transcriptional regulation of germinal center formation. Front. Immunol. 9:2026. https://doi.org/10.3389/ fimmu.2018.02026

Spaccapelo, R., C.J. Janse, S. Caterbi, B. Franke-Fayard, J.A. Bonilla, L.M. Syphard, M. Di Cristina, T. Dottorini, A. Savarino, A. Cassone, et al. 2010. Plasmepsin 4-Deficient Plasmodium berghei Are Virulence Attenuated and Induce Protective Immunity against Experimental Malaria. Am. J. Pathol. 176(1):205-217. https://doi.org/10.2353/ajpath.2010 .090504

Subramanian, A., P. Tamayo, V.K. Mootha, S. Mukherjee, B.L. Ebert, M.A. Gillette, A. Paulovich, S.L. Pomeroy, T.R. Golub, E.S. Lander, et al. 2005. Gene set enrichment analysis: a knowledge-based approach for interpreting genome-wide expression profiles. Proc. Natl. Acad. Sci. USA. 102: 15545-15550. https://doi.org/10.1073/pnas.0506580102

Suzuki, T., H. Oshiumi, M. Miyashita, H.H. Aly, M. Matsumoto, and T. Seya. 2013. Cell type-specific subcellular localization of phospho-TBK1 in response to cytoplasmic viral DNA. PLoS One. 8:e83639. https://doi.org/ 10.1371/journal.pone.0083639

Taylor, J.J., K.A. Pape, and M.K. Jenkins. 2012. A germinal centerindependent pathway generates unswitched memory B cells early in the primary response. J. Exp. Med. 209:597-606. https://doi.org/10 $.1084 /$ jem.20111696

Tomayko, M.M., N.C. Steinel, S.M. Anderson, and M.J. Shlomchik. 2010. Cutting edge: hierarchy of maturity of murine memory B cell subsets. J. Immunol. 185:7146-7150. https://doi.org/10.4049/jimmunol.1002163

Victora, G.D., and M.C. Nussenzweig. 2012. Germinal centers. Annu. Rev. Immunol. 30:429-457. https://doi.org/10.1146/annurev-immunol-020711 $-075032$

Victora, G.D., T.A. Schwickert, D.R. Fooksman, A.O. Kamphorst, M. MeyerHermann, M.L. Dustin, and M.C. Nussenzweig. 2010. Germinal center dynamics revealed by multiphoton microscopy with a photoactivatable fluorescent reporter. Cell. 143:592-605. https://doi.org/10.1016/j.cell .2010.10.032

Vogelzang, A., H.M. McGuire, D. Yu, J. Sprent, C.R. Mackay, and C. King. 2008. A Fundamental role for interleukin-21 in the generation of $\mathrm{T}$ follicular helper cells. Immunity. 29:127-137. https://doi.org/10.1016/j .immuni.2008.06.001

Weiss, G.E., P.D. Crompton, S. Li, L.A. Walsh, S. Moir, B. Traore, K. Kayentao, A. Ongoiba, O.K. Doumbo, and S.K. Pierce. 2009. Atypical memory B cells are greatly expanded in individuals living in a malaria-endemic area. J. Immunol. 183:2176-2182. https://doi.org/10.4049/jimmunol .0901297

Willis, S.N., K.L. Good-Jacobson, J. Curtis, A. Light, J. Tellier, W. Shi, G.K. Smyth, D.M. Tarlinton, G.T. Belz, L.M. Corcoran, et al. 2014. Transcription factor IRF4 regulates germinal center cell formation through a B cell-intrinsic mechanism. J. Immunol. 192:3200-3206. https://doi.org/ 10.4049/jimmunol.1303216

Wing, J.B., Y. Kitagawa, M. Locci, H. Hume, C. Tay, T. Morita, Y. Kidani, K. Matsuda, T. Inoue, T. Kurosaki, et al. 2017. A distinct subpopulation of -D25- T-follicular regulatory cells localizes in the germinal centers.
Proc. Natl. Acad. Sci. USA. 114:E6400-E6409. https://doi.org/10.1073/ pnas. 1705551114

Workman, L.M., L. Zhang, Y. Fan, W. Zhang, and H. Habelhah. 2020. TRAF2 Ser-11 phosphorylation promotes cytosolic translocation of the CD40 complex to regulate downstream signaling pathways. Mol. Cell. Biol. 40:e00429-19. https://doi.org/10.1128/MCB.00429-19

Xiao, Y., Q. Zou, X. Xie, T. Liu, H.S. Li, Z. Jie, J. Jin, H. Hu, G. Manyam, L. Zhang, et al. 2017. The kinase TBK1 functions in dendritic cells to regulate $\mathrm{T}$ cell homeostasis, autoimmunity, and antitumor immunity. J. Exp. Med. 214:1493-1507. https://doi.org/10.1084/jem.20161524

Xie, X., D. Zhang, B. Zhao, M.K. Lu, M. You, G. Condorelli, C.Y. Wang, and K.L. Guan. 2011. I B kinase $\varepsilon$ and TANK-binding kinase 1 activate AKT by direct phosphorylation. Proc. Natl. Acad. Sci. USA. 108:6474-6479. https://doi.org/10.1073/pnas.1016132108

Yam-Puc, J.C., L. Zhang, R.A. Maqueda-Alfaro, L. Garcia-Ibanez, Y. Zhang, J. Davies, Y.A. Senis, M. Snaith, and K.M. Toellner. 2021. Enhanced BCR signaling inflicts early plasmablast and germinal center B cell death. iScience. 24:102038. https://doi.org/10.1016/j.isci.2021.102038

Yamagishi, J., A. Natori, M.E.M. Tolba, A.E. Mongan, C. Sugimoto, T. Katayama, S. Kawashima, W. Makalowski, R. Maeda, Y. Eshita, et al. 2014 Interactive transcriptome analysis of malaria patients and infecting Plasmodium falciparum. Genome Res. 24:1433-1444. https://doi.org/10 $.1101 /$ gr.158980.113

Yu, J., X. Zhou, M. Chang, M. Nakaya, J.-H. Chang, Y. Xiao, J. William Lindsey, S. Dorta-Estremera, W. Cao, A. Zal, et al. 2015. Regulation of T-cell activation and migration by the kinase TBK1 during neuroinflammation. Nat. Commun. 6:6074. https://doi.org/10.1038/ncomms7074

Zander, R.A., N. Obeng-Adjei, J.J. Guthmiller, D.I. Kulu, J. Li, A. Ongoiba, B. Traore, P.D. Crompton, and N.S. Butler. 2015. PD-1 Co-inhibitory and OX40 Co-stimulatory Crosstalk Regulates Helper T Cell Differentiation and Anti-Plasmodium Humoral Immunity. Cell Host Microbe. 17:628-641. https://doi.org/10.1016/j.chom.2015.03.007

Zarnegar, B., J.Q. He, G. Oganesyan, A. Hoffmann, D. Baltimore, and G. Cheng. 2004. Unique CD40-mediated biological program in B cell activation requires both type 1 and type 2 NF-kB activation pathways. Proc. Natl. Acad. Sci. USA. 101:8108-8113. https://doi.org/10.1073/pnas.0402629101

Zhang, T.T., D.G. Gonzalez, C.M. Cote, S.M. Kerfoot, S. Deng, Y. Cheng, M. Magari, and A.M. Haberman. 2017. Germinal center B cell development has distinctly regulated stages completed by disengagement from $\mathrm{T}$ cell help. eLife. 6:e19552. https://doi.org/10.7554/eLife.19552

Zhao, P., K.I. Wong, X. Sun, S.M. Reilly, M. Uhm, Z. Liao, Y. Skorobogatko, and A.R. Saltiel. 2018. TBK1 at the crossroads of inflammation and energy homeostasis in adipose tissue. Cell. 172:731-743.e12. https://doi.org/ 10.1016/j.cell.2018.01.007

Zhu, Z., A. Shukla, P. Ramezani-Rad, J.R. Apgar, and R.C. Rickert. 2019. The AKT isoforms 1 and 2 drive $B$ cell fate decisions during the germinal center response. Life Sci. Alliance. 2:e201900506. https://doi.org/10 $.26508 / \mathrm{lsa} .201900506$

Zuccarino-Catania, G.V., S. Sadanand, F.J. Weisel, M.M. Tomayko, H. Meng, S.H. Kleinstein, K.L. Good-Jacobson, and M.J. Shlomchik. 2014. CD80 and PD-L2 define functionally distinct memory B cell subsets that are independent of antibody isotype. Nat. Immunol. 15:631-637. https://doi .org/10.1038/ni.2914 


\section{Supplemental material}


A

Parasitemia

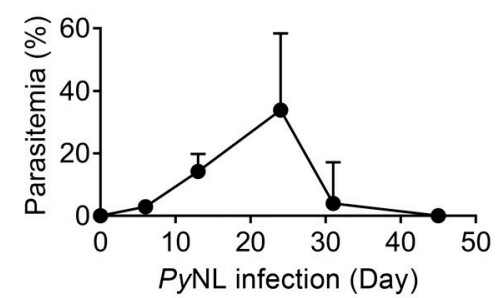

B
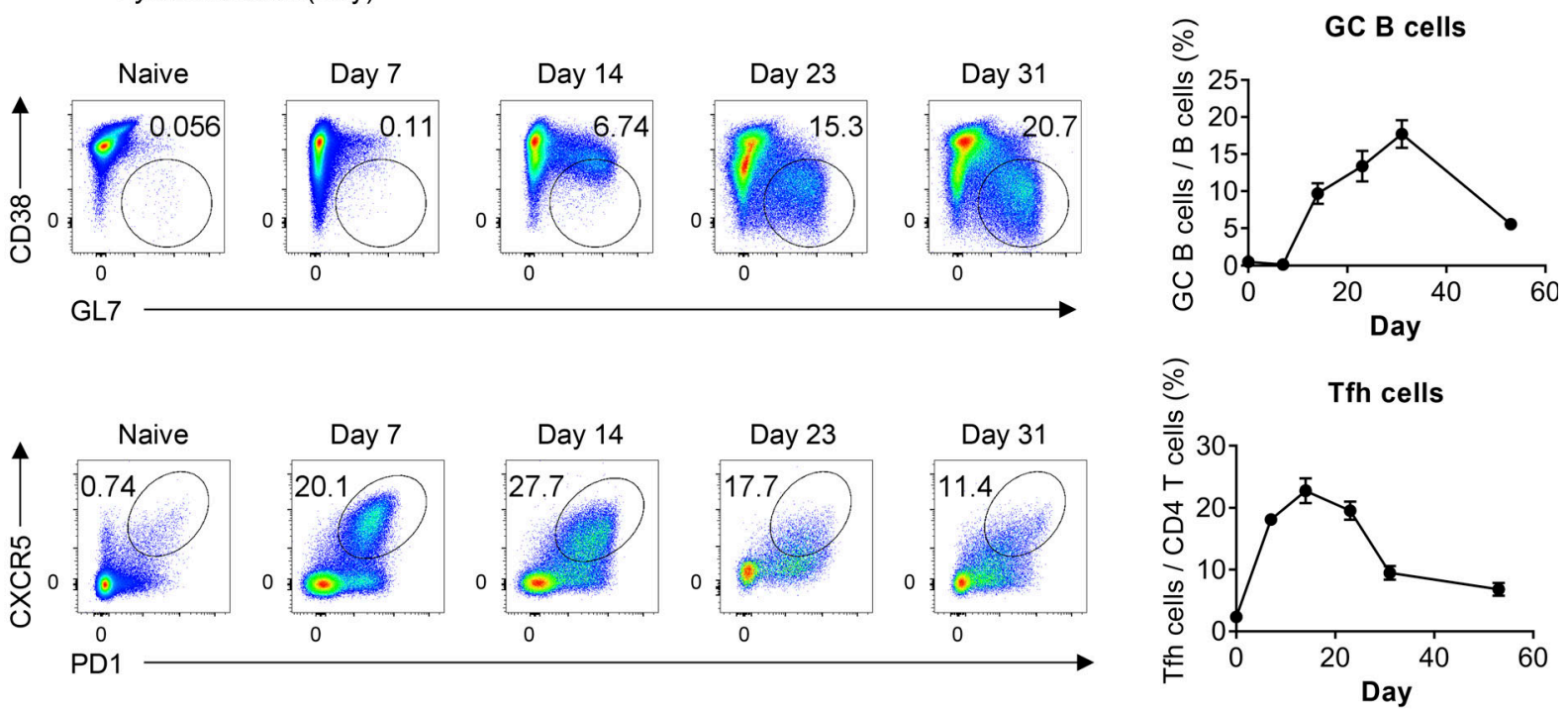

C

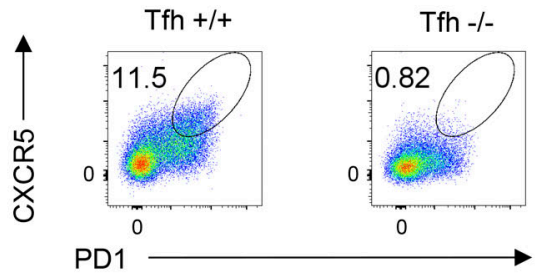

E

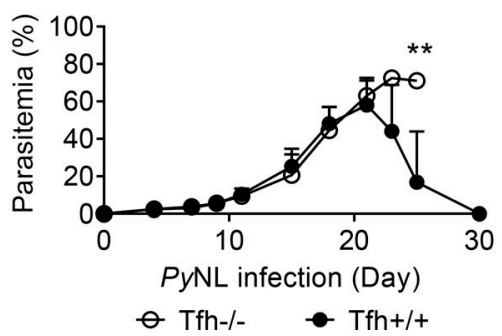

D

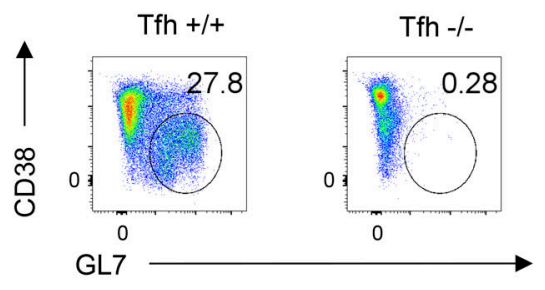

Survival

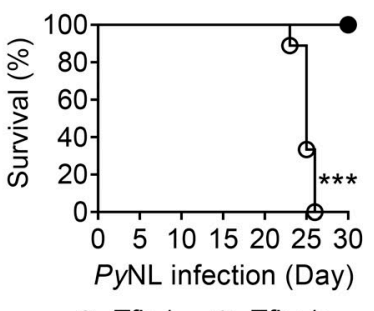

$\ominus$ Tfh-/- $\bullet \mathrm{Tfh}+/+$

Figure S1. Tfh cells and GC formation are essential for recovery from PyNL infection. (A) Parasitemia of WT mice infected with PyNL. $n=24$ mice pooled from four independent experiments. (B) Time-course analysis of Tfh cells and GC formation in the spleens of WT mice infected with PyNL. $n=4-5$ mice per time point from four independent experiments. (C and D) Representative FACS plots of Tfh (C) and GC (D) populations in the spleens of $C d 4^{c r e} B c / 6^{f / f}\left(T f h h^{-/-}\right.$) mice and $C d 4^{\mathrm{wt}} B c l 6^{\mathrm{f} / \mathrm{f}}\left(\mathrm{Tfh}^{+/+}\right)$mice infected with PyNL. $n=4$ mice/group representative of two independent experiments. (E) Parasitemia and survival of Tfh ${ }^{-/-}$ mice and Tfh ${ }^{+/+}$mice infected with PyNL. $n=9-10$ mice/group pooled from two independent experiments. Each dot represents data from an individual mouse. Data are pooled from four independent experiments ( $A$ and $B$ ) or representative of two independent experiments $(C$ and $D)$. Data are shown as mean $\pm \mathrm{SD} .{ }^{* *}, \mathrm{P}<0.01 ;{ }^{* * *}, \mathrm{P}<0.001 ;$ Mann-Whitney $t$ test $(\mathrm{E})$, log-rank (Mantel-Cox) test (E). 
A

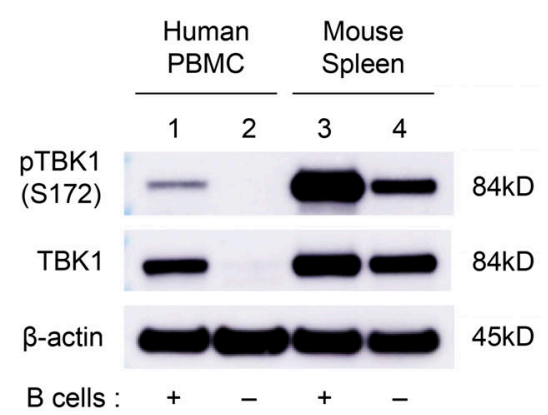

B

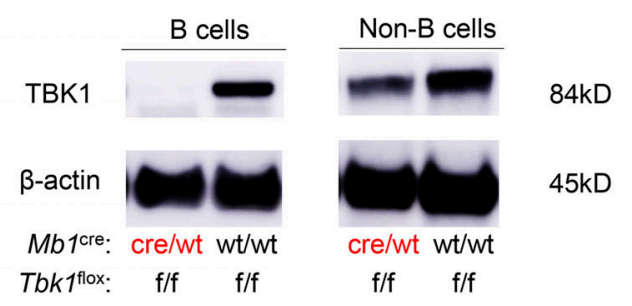

\section{C}

Spleen :

B Tbk1-I-

B Tbk1+/+

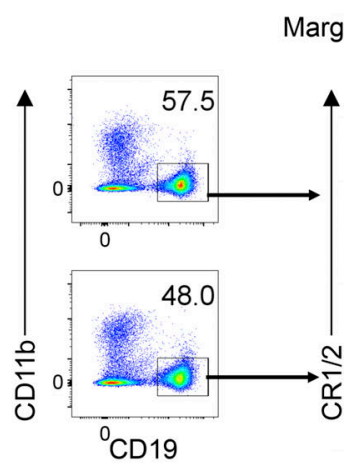

Marginal zone $B$ cells

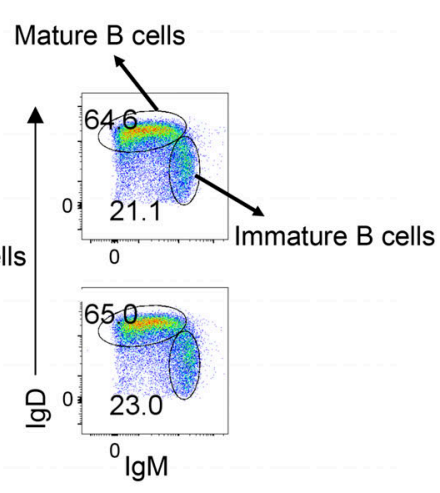

D

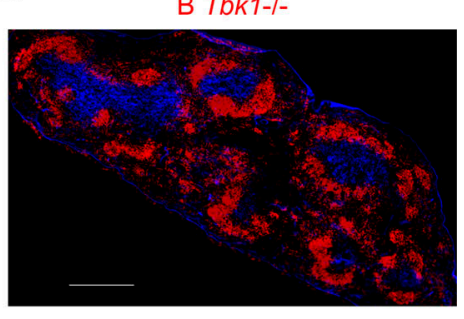

B Tbk1+/+

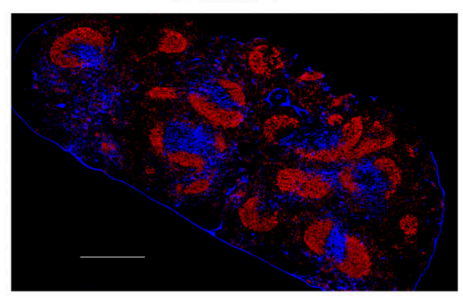

CD4 IgD
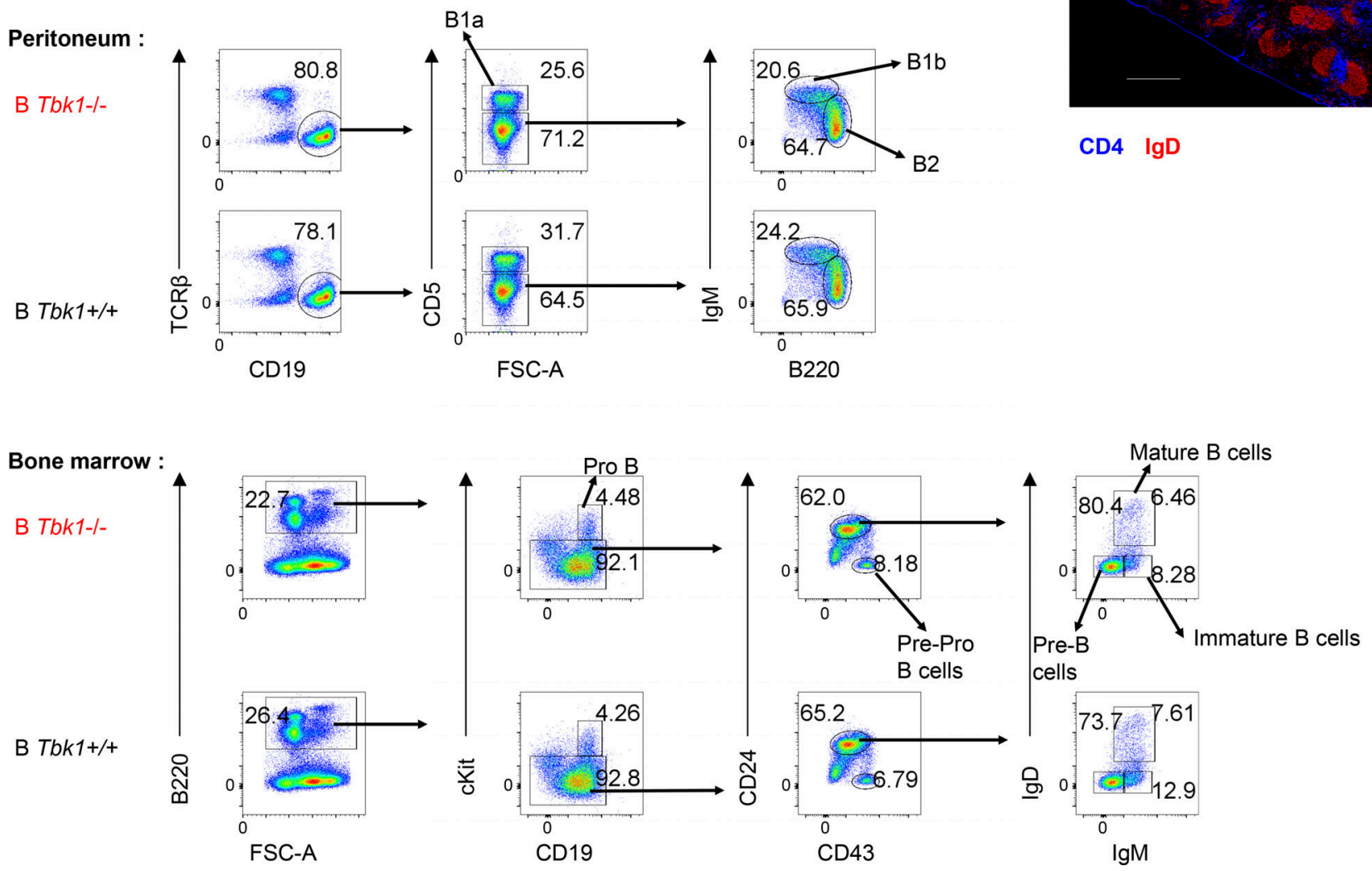

Figure S2. TBK1 expression in B cell and deletion efficiency in B cells and T cells using a Cre-loxP system. (A) Expression and phosphorylation of TBK1 in human B cells from PBMCs and mouse splenic B cells by immunoblotting. (B) Depletion efficiency of TBK1 in splenic B cells was analyzed by immunoblotting.

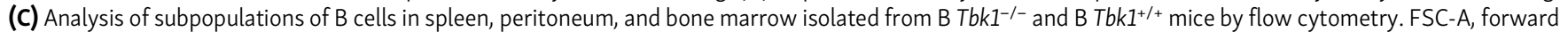

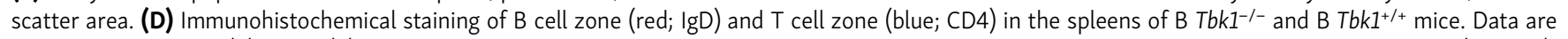
representative of two (A) or five (B) independent experiments or from one experiment with a representative of three independent biological samples (C and D). Scale bars, $500 \mu \mathrm{m}$. Source data are available for this figure: SourceData FS2. 
A Primary PyNL infection:
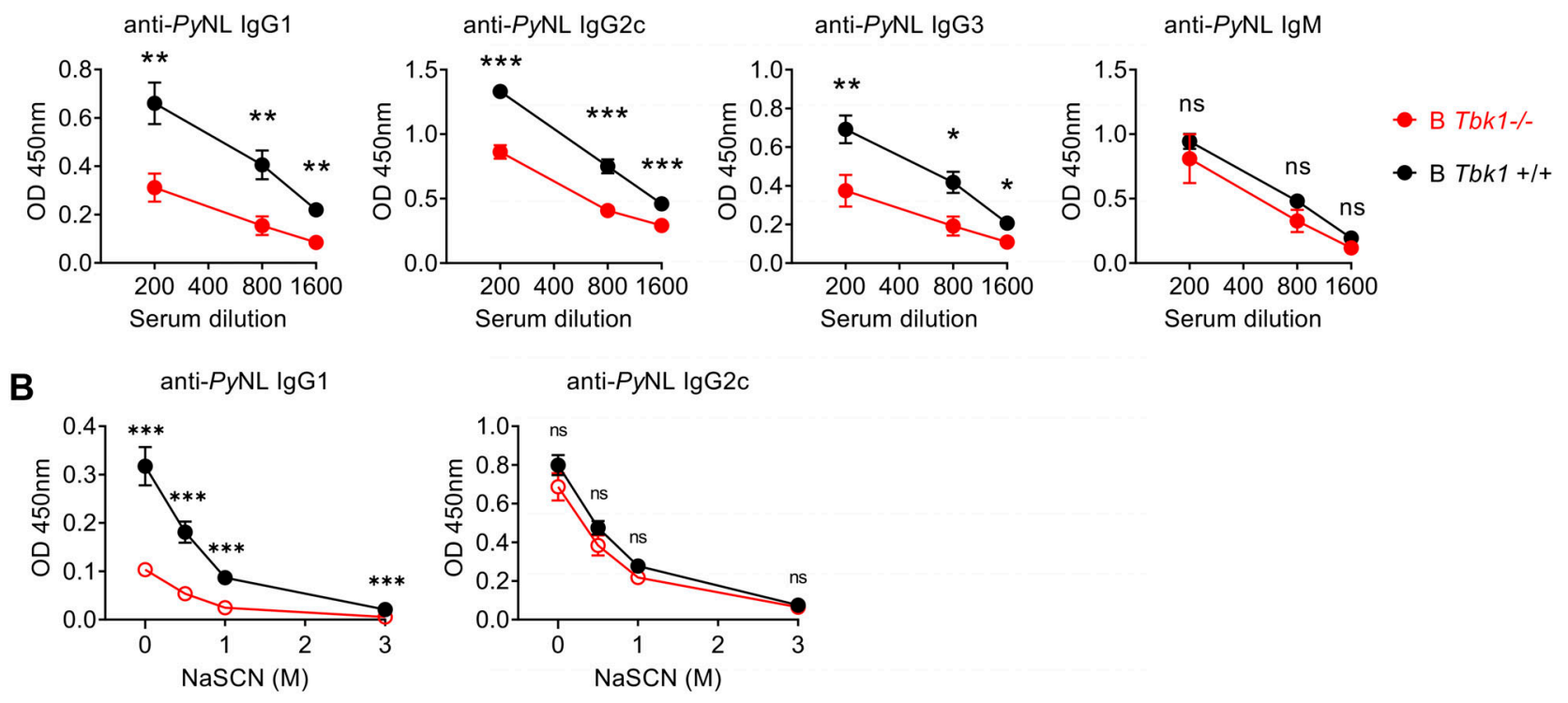

C Anti-NP30 Total IgG

Anti-NP30 lgG1

Anti-NP30 lgG2c

Anti-NP30 IgM
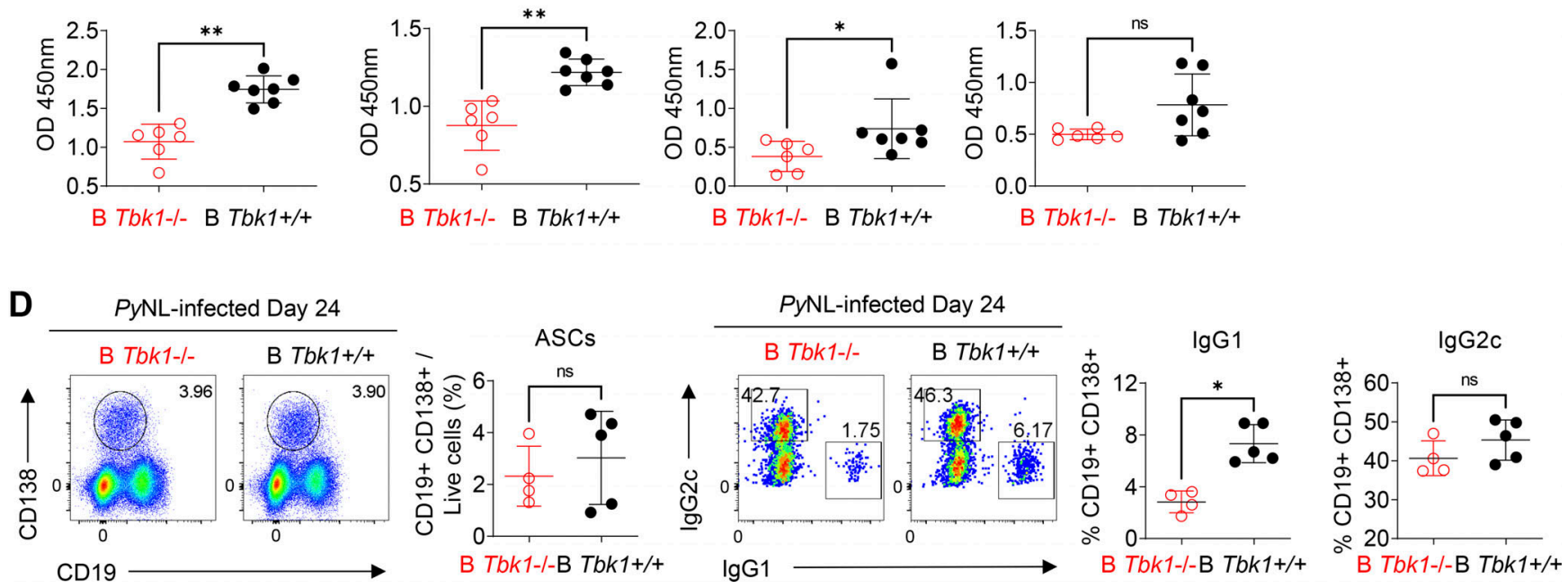

Figure S3. B Tbk1 $\mathbf{1}^{-1-}$ mice could produce antigen-specific antibodies, albeit less of them, despite the lack of GC formation. (A) PyNL-specific serum antibody measurement by ELISA on days 28-35 after infection with PyNL. $n=6-10$ mice/group from three independent experiments. (B) Avidity assay of PyNLspecific serum antibody on days 19-35 after infection with PyNL. $n=10-12$ mice/group from five independent experiments. (C) NP 30 (4-hydroxy-3-nitrophenylacetyl hapten conjugated BSA ratio 30)-specific serum antibody measurement by ELISA on day 21 after immunization with NIP-OVA with alum i.d. $n=$ 6-7 mice/group representative of two independent experiments. (D) ASC population in the spleens of PyNL-infected mice on day 24 analyzed by FACS. $n=4-5$ mice/group representative of two independent experiments. Each dot represents data from an individual mouse. Data are pooled from three (A) or five (B) independent experiments and representative of two independent experiments ( $C$ and $D)$. Data are shown as mean $\pm S D .{ }^{*}, P<0.05 ;{ }^{* *}, P<0.01 ;{ }^{* * *}, P<0.001$; Mann-Whitney $t$ test (A-D). 
A $\begin{gathered}\text { Regulation of } \\ \text { signal transduction }\end{gathered}$

B Tbk1+/+ B Tbk1-/-

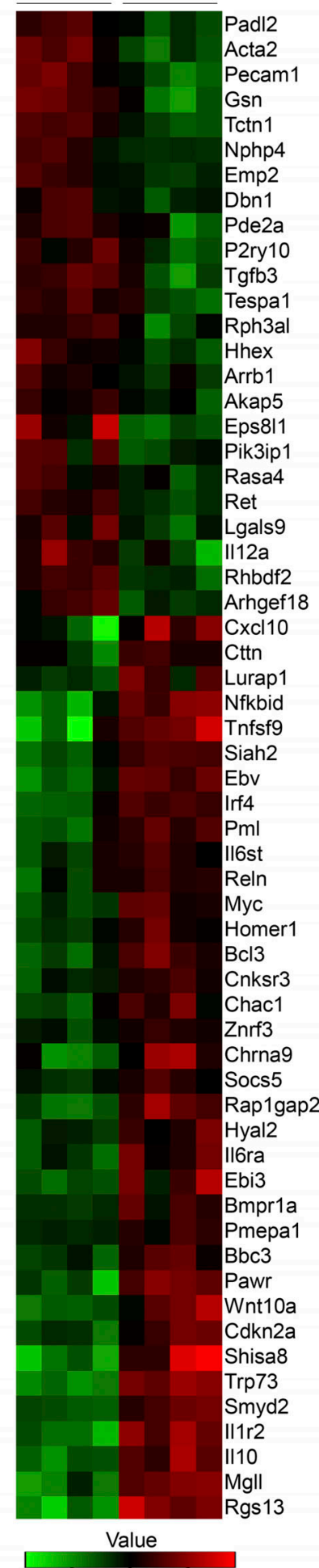

$\begin{array}{lll}-0.5 & 0 & 0.5\end{array}$

NES $=2.2645$

nGenes $=60$

Adj. Pval $=0.035$
B $\begin{gathered}\text { Up-regulated } \\ \text { by CD40 stimulation }\end{gathered}$

B Tbk1+/+ B Tbk1-/-

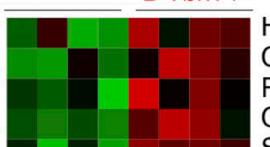

Hk2

Pecr

Cond2

Shmt1

Tex2

Lman1

Ifrd2

Ppid

Akap1

Ube2e3

Lyar

Lap3

Gfpt1

C1qbp

$\mathrm{Ncl}$

Atp2a2

Nolc1

Pitrm1

Ranbp1

Prps1

Eprs

Mrps2

Apex1

Rps271

Fkbp1a

Nars

H2afz

Snrpa1

Fbl

Slc25a19

Eif4e

Gtf2i

Metap1

Idh3a

IIf2

Elavl1

Cnbp

Cct8

Snrpd1

Cycs

2810004N23Rik

Txn1

Tfdp1

Eif2a

Ppm1g

Psmd11

Nfkb1

H2-D1

Cd79a

Expression $\left(\log _{2}\right)$

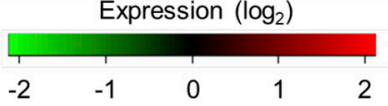

Up-regulated

by BCR stimulation

B Tbk1+/+ B Tbk1-I-

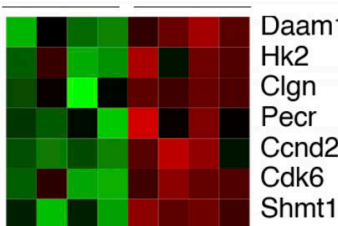

Shmt

Tex2

Ifrd2

Sssca1

Timm9

Akap1

Lyar

Lap3

Gfpt1

C1qbp

$\mathrm{Ncl}$

Atp2a2

Nolc1

Pitrm1

Ranbp1

Prps1

Eprs

Mrps2

Rps27I

Hbs1l

Txnrd1

Fkbp1a

Nars

H2afz

Snrpa1

Eif4e

Sfxn1

Metap1

Idh3a

Bcas2

Strap

Elavl1

Dnaja3

Snrpd1

Cycs

2810004N23Rik

Tfdp1

Eif2a

Ppm1g

Stxbp3

H2-D1

Satb1

Cd72

Ephx1

Figure S4. TBK1 negatively regulates CD40 and BCR signaling. (A) Heatmap of GO biological process pathway analysis by GSEA (preranked fast GSEA) based on RNA-seq analysis. (B) TBK1-dependent genes up-regulated by CD40 or BCR stimulation in Pre-GC analyzed by GSEA based on RNA-seq data (related to Fig. 4 I). Data are from one experiment. $n=4$ mice/group. NES, normalized enrichment score. 


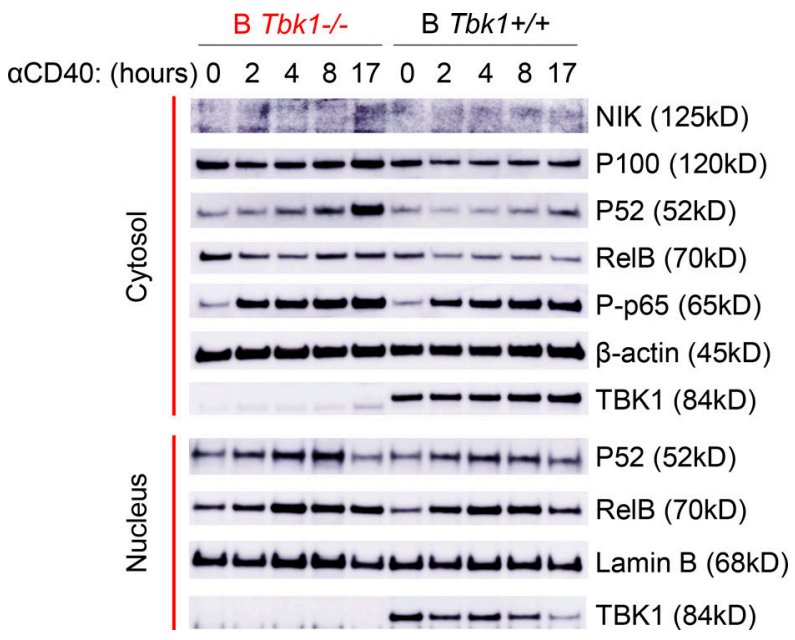

Figure S5. TBK1 negatively regulates CD40-induced noncanonical NF-KB signaling in B cells. Time-course analysis of cytosolic and nuclear fractions of

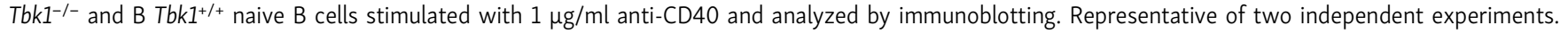
Source data are available for this figure: SourceData FS5.

Provided online is one table. Table S1 provides RNA-seq data of Pre-GC isolated from B Tbk1-/- mice versus B Tbk1 ${ }^{+/+}$mice on day 9 post-PyNL infection. 